\title{
Synthesis of Salicaceae Acetyl Salicins Using Selective Deacetylation and Acetyl Group Migration
}

Dariya A. Romanova, ${ }^{\dagger}$ David L. Avetyan, ${ }^{\dagger},+$ Maxim L. Belyanin, $^{\dagger}$ and Elena V. Stepanova ${ }^{*, \dagger, \S}$ ${ }^{\dagger}$ Tomsk Polytechnic University, Lenin Avenue 30, Tomsk 634050, Russian Federation ¥ Siberian State Medical University, Moskovskiy Trakt 2, Tomsk 634050, Russian Federation

$\S$ N. D. Zelinsky Institute of Organic Chemistry of the Russian Academy of Sciences, Leninsky Prospect 47, Moscow 119991, Russian Federation

\section{Supporting Information}

\section{Corresponding Author}

*Tel (Elena V. Stepanova): +7 (3822) 563861. E-mail: eline_m@mail.ru, glycoside.m@gmail.com. 


\section{Content}

$\mathrm{S} 1 \mathrm{The}$ assignment of all protons for compounds $4,6,7$, including $\mathrm{OH}$ peaks...................

S1 NMR data for 2-(Bromomethyl)phenyl-2,3,4,6-tetra-O-acetyl- $\beta$-D-glucopyranoside (2) .....4

S2 NMR data for 2-(Dibromomethyl)phenyl-2,3,4,6-tetra-O-acetyl- $\beta$-D-glucopyranoside (2a)...8

S3 NMR data for 2-(Chloromethyl)phenyl-2,3,4,6-tetra-O-acetyl- $\beta$-D-glucopyranoside (3).....12

S4 NMR data for 2-(Ethoxymethyl)phenyl-2-O-acetyl- $\beta$-D-glucopyranoside (4) $\ldots \ldots \ldots \ldots \ldots 16$

S5 NMR data for 2-(Chloromethyl)phenyl-2-O-acetyl- $\beta$-D-glucopyranoside (5) $\ldots \ldots \ldots \ldots \ldots . . .20$

S6 NMR data for 2-(Hydroxymethyl)phenyl-2-O-acetyl- $\beta$-D-glucopyranoside

(2-O-acetylsalicin) $(\mathbf{6})$ .25

S7 NMR data for 2-(Ethoxymethyl)phenyl-6-O-acetyl- $\beta$-D-glucopyranoside (7) 30

S8 NMR data for2-(Chloromethyl)phenyl-6-O-acetyl- $\beta$-D-glucopyranoside (8) 34

S9 NMR data for 2-(Hydroxymethyl)phenyl-6-O-acetyl- $\beta$-D-glucopyranoside (Fragilin) (9)....38

S10 NMR data for 2-(Ethoxymethyl)phenyl- $\beta$-D-glucopyranoside (Ethylsalicin) (10) 43

S11 NMR data for 2-(Chloromethyl)phenyl- $\beta$-D-glucopyranoside (Chlorosalicin) (11) 47

S12 NMR data for 2-(Hydroxymethyl)phenyl- $\beta$-D-glucopyranoside (Salicin) (12) 51 
S1 The assignment of all protons for compounds 4, 6, 7, including $\mathrm{OH}$ peaks.

2-(Ethoxymethyl)phenyl-2-O-acetyl- $\boldsymbol{\beta}$-D-glucopyranoside (4). ${ }^{1} \mathrm{H}$ NMR (400 MHz, DMSO, $\delta$, ppm, $J, \mathrm{~Hz}): 1.15\left(\mathrm{t}, 3 \mathrm{H}, J\right.$ 7.0, $\left.\mathrm{CH}_{2} \mathrm{CH}_{3}\right), 2.05$ (s, 3H, $\left.\mathrm{COOCH}_{3}\right), 3.28(\mathrm{dd}, 1 \mathrm{H}, J$ 5.7, J 9.1, H4), 3.46 (q, 1H, J 7.0, $\mathrm{CH}_{2} \mathrm{CH}_{3}$ ), 3.48-3.54 (m, 3H, H-3, H-5, H-6a), 3.73 (dd, 1H, J 5.5, J 11.0, H-6b), 4.32 (s, 1H, CH $\left.H_{2} \mathrm{OEt}\right), 4.69$ (t, 1H, J 5.5, OH-6), 4.81 (dd, 1H, J 8.0, J 9.3, H-2), 5.09 (d, $1 \mathrm{H}, J$ 8.0, H-1), 5.30 (d, 1H, J 5.3, OH-4), 5.40 (d, 1H, J 5.4, OH-3), 7.02 (dd t, 1H, J 7.3, $\left.\mathrm{C}_{6} H_{4}\right), 7.11\left(\mathrm{~d}, 1 \mathrm{H}, J 8.3, \mathrm{C}_{6} H_{4}\right), 7.24\left(\mathrm{dd} \sim \mathrm{t}, 1 \mathrm{H}, J 7.9, \mathrm{C}_{6} H_{4}\right), 7.31\left(\mathrm{~d}, 1 \mathrm{H}, J 7.7, \mathrm{C}_{6} H_{4}\right)$.

2-(Hydroxymethyl)phenyl-2-O-acetyl- $\beta$-D-glucopuranose (2-O-acetylsalicin) (6). ${ }^{1} \mathrm{H} \mathrm{NMR}$ (400 MHz, DMSO, $\delta$, ppm, J, Hz): 2.04 (s, 3H, COOCH ${ }_{3}$ ), 3.26 (br dd t, 1H, J 9.4, H-4), 3.383.56 (m, 3H, H-3, H-5, H-6a), 3.72 (dd, 1H, J 5.0, J 11.6, H-6b), 4.34 (dd, 1H, J 5.0, J 14.9, $\left.\mathrm{CH}_{2} \mathrm{OH}\right), 4.40(\mathrm{dd}, 1 \mathrm{H}, J$ 5.0, $J$ 14.9, CH2OH), 4.68 (t, 1H, J 5.0, OH-6), 4.72 (dd, 1H, J 8.1, $J$ 9.1, H-2), $5.00\left(\mathrm{t}, 1 \mathrm{H}, J\right.$ 5.0, $\left.\mathrm{CH}_{2} \mathrm{OH}\right), 5.04(\mathrm{~d}, 1 \mathrm{H}, J$ 8.1, H-1), 5.30 (d, 1H, J 4.2, OH-4), 5.39 $(\mathrm{d}, 1 \mathrm{H}, J 4.7, \mathrm{OH}-3), 7.02$ (dd t, $\left.1 \mathrm{H}, J 7.4, \mathrm{C}_{6} H_{4}\right), 7.06\left(\mathrm{~d}, 1 \mathrm{H}, J 8.1, \mathrm{C}_{6} H_{4}\right), 7.18(\mathrm{dd} \sim \mathrm{t}, 1 \mathrm{H}, J$ 7.6, $\left.\mathrm{C}_{6} H_{4}\right), 7.39\left(\mathrm{~d}, 1 \mathrm{H}, J 7.5, \mathrm{C}_{6} H_{4}\right)$.

2-(Ethoxymethyl)phenyl-6-O-acetyl- $\beta$-D-glucopyranoside (7). ${ }^{1} \mathrm{H}$ NMR (400 MHz, DMSO, $\delta$, ppm, $J, \mathrm{~Hz}): 1.16\left(\mathrm{t}, 3 \mathrm{H}, J\right.$ 7.0, $\left.\mathrm{CH}_{2} \mathrm{CH}_{3}\right), 2.00\left(\mathrm{~s}, 3 \mathrm{H}, \mathrm{COOCH}_{3}\right), 3.18$ (ddd, 1H, J 5.3, J 8.9, J 9.1, H-4), 3.23-3.30 (m, 2H, H-2, H-3), 3.50 (q, 3H, J 7.0, $\mathrm{CH}_{2} \mathrm{CH}_{3}$ ), 3.58 (dd, $1 \mathrm{H}, J$ 6.8, J 8.9, H-5), 4.09 (dd, 1H, J 6.8, J 11.8, H-6a), 4.27 (d, 1H, J 11.8, H-6b), 4.49 (d, 1H, J 13.1, CH $\mathrm{H}_{2} \mathrm{OEt}$ ), 4.54 (d, 1H, J 13.1, $\left.\mathrm{CH}_{2} \mathrm{OEt}\right), 4.82(\mathrm{~d}, 1 \mathrm{H}, J$ 6.8, H-1), $5.21(\mathrm{~d}, 1 \mathrm{H}, J 3.3, \mathrm{OH}-2), 5.30$ (d, 1H, $J$ 5.3, OH-4), 5.35 (d, 1H, J 3.6, OH-3), 7.01 (dd t, $\left.1 \mathrm{H}, J 7.4, \mathrm{C}_{6} H_{4}\right), 7.05$ (d, 1H, J 8.3, $\left.\mathrm{C}_{6} H_{4}\right)$, $7.23\left(\mathrm{dd} \sim \mathrm{t}, 1 \mathrm{H}, J 7.6, \mathrm{C}_{6} H_{4}\right), 7.32\left(\mathrm{~d}, 1 \mathrm{H}, J 7.4, \mathrm{C}_{6} H_{4}\right)$. 
우우씼

NNNNNNNNNNNNNNN

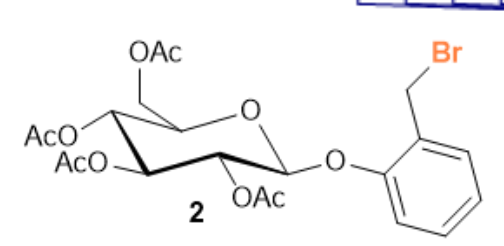

${ }^{1} \mathrm{H}\left(400 \mathrm{MHz}, \mathrm{CDCl}_{3}\right)$

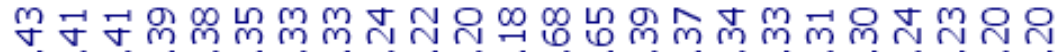

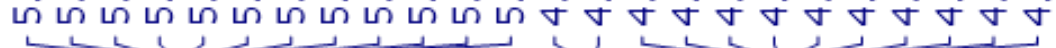

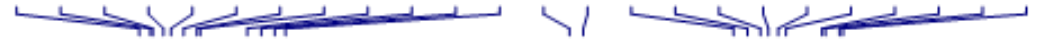

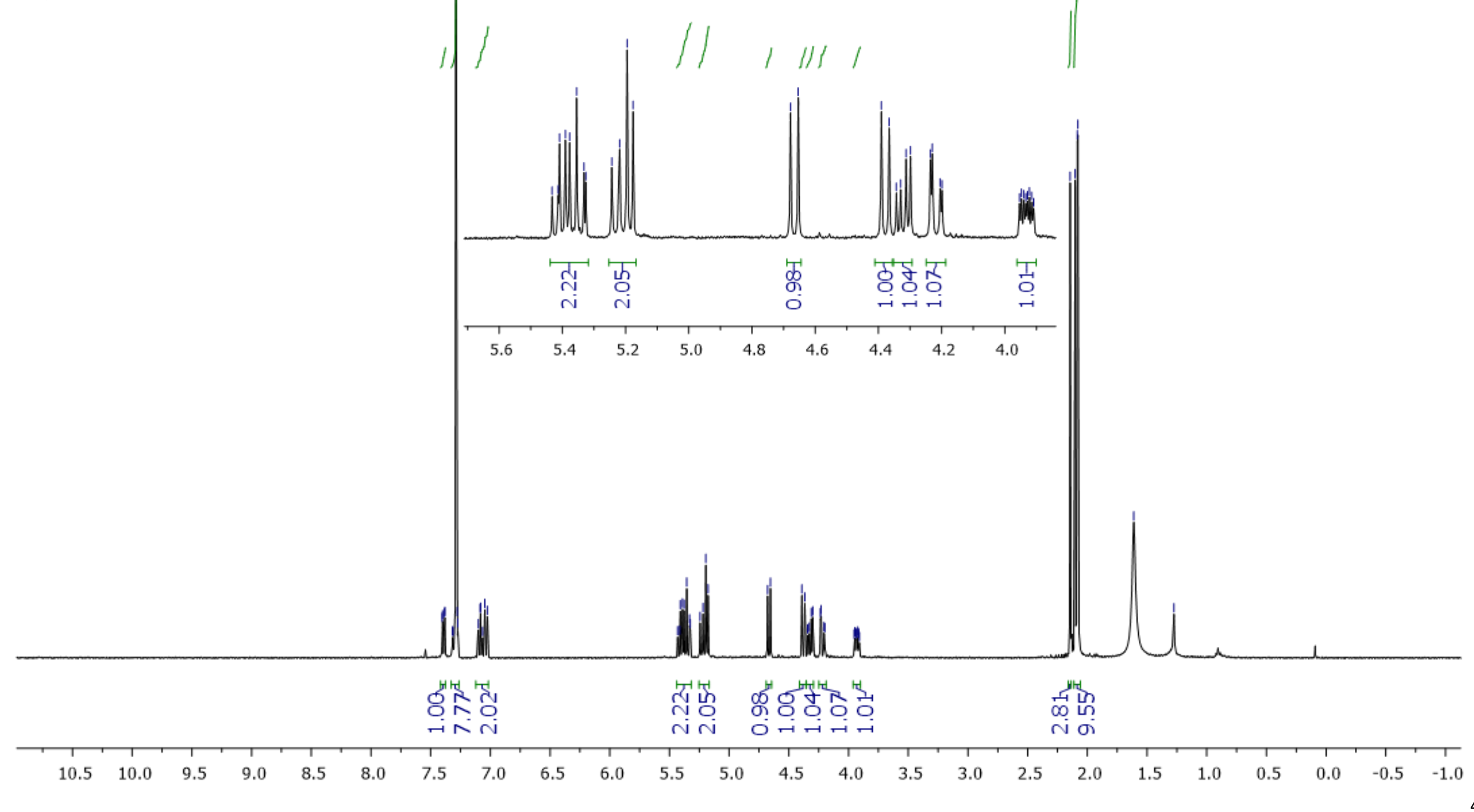


นกำํำ ำ

옴임

4

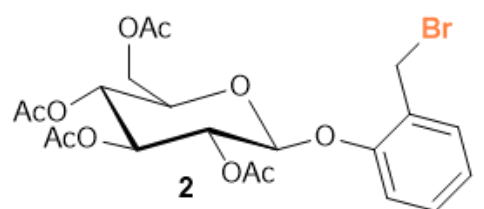

${ }^{13} \mathrm{C}\left(100 \mathrm{MHz}, \mathrm{CDCl}_{3}\right)$
กิํํำ

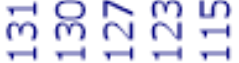

1)

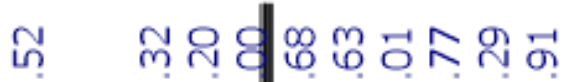

Кลำกำ

।

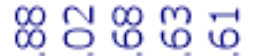

ลี่ำำ

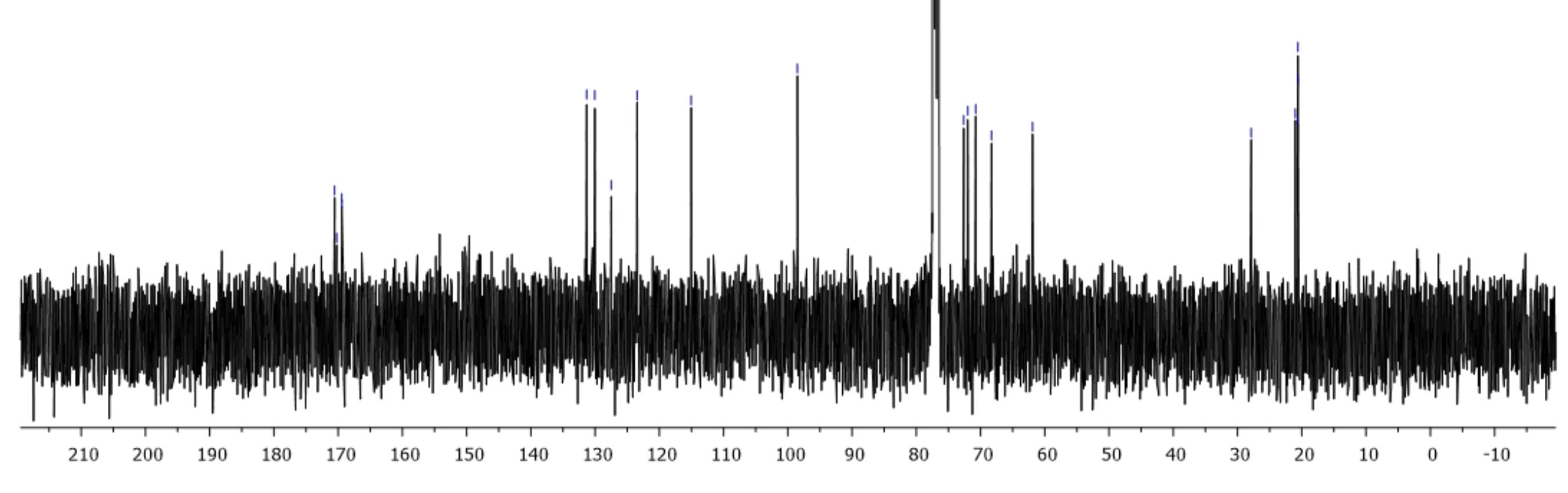


${ }^{1} \mathrm{H}-{ }^{1} \mathrm{H}$ COSY

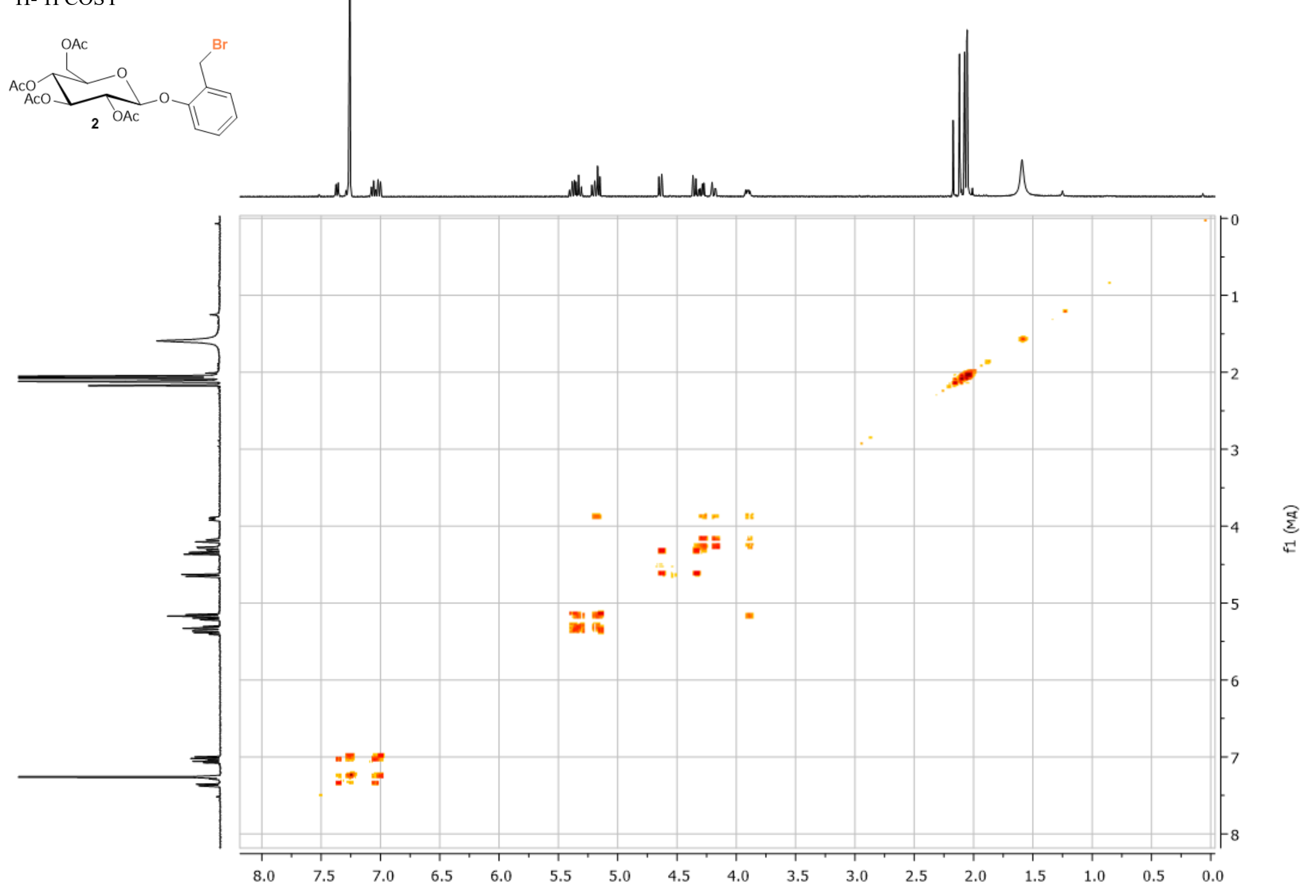




$$
10
$$


${ }^{1} \mathrm{H}\left(400 \mathrm{MHz}, \mathrm{CDCl}_{3}\right)$

\section{구요}

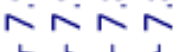

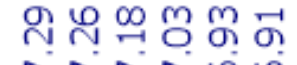

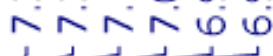

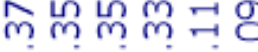

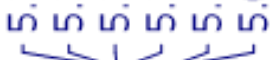

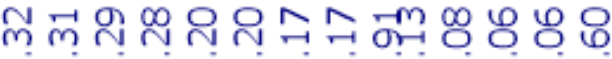

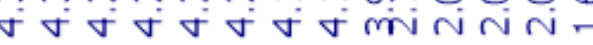

।

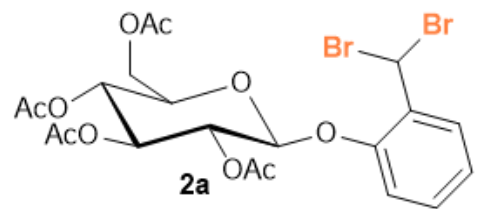

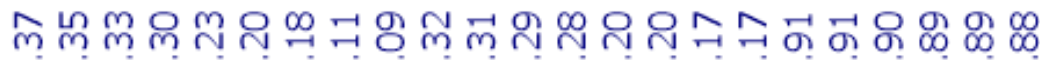

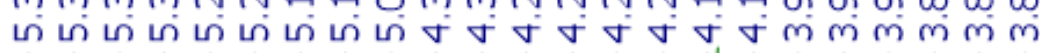

1 ill?
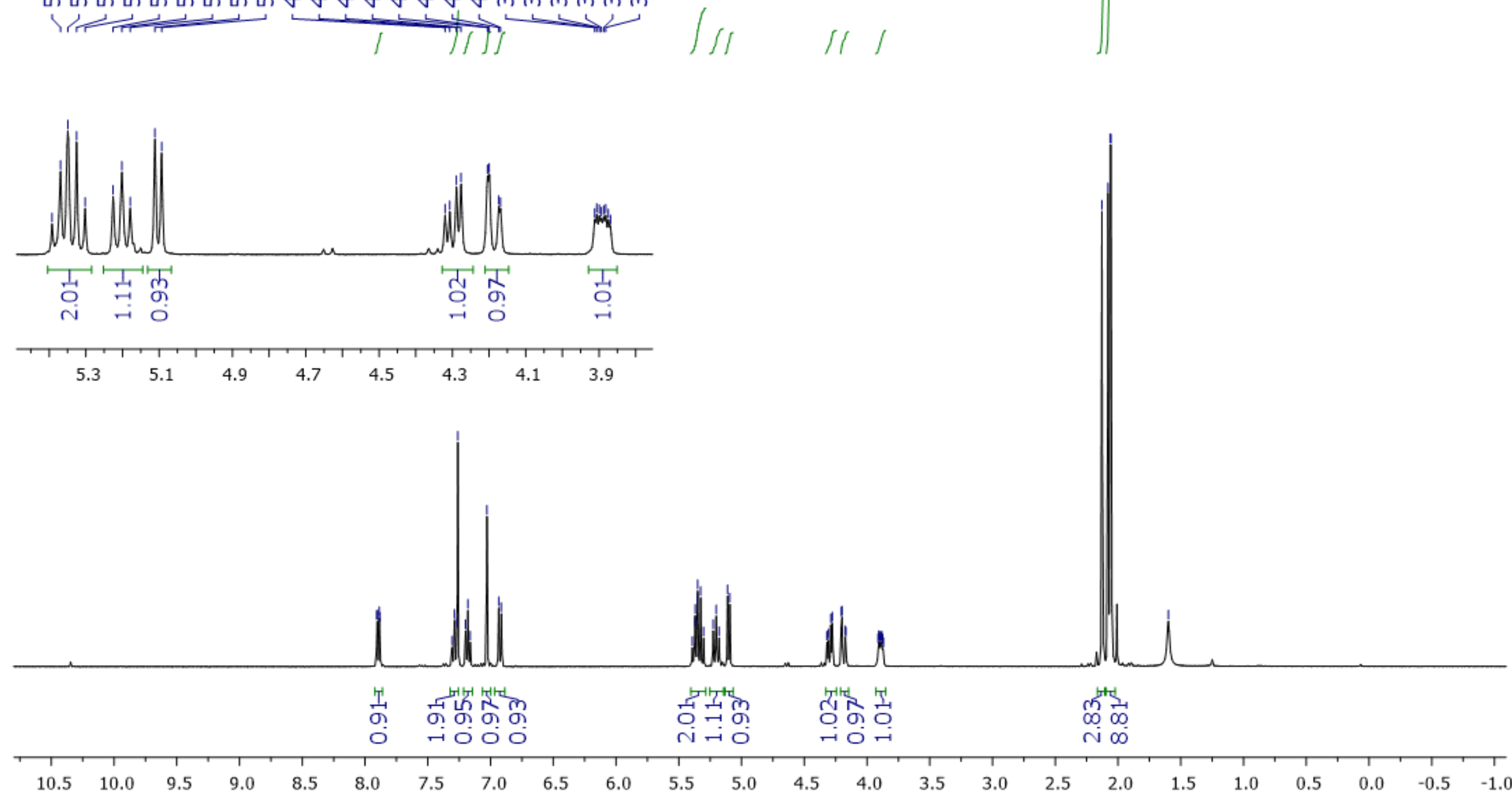


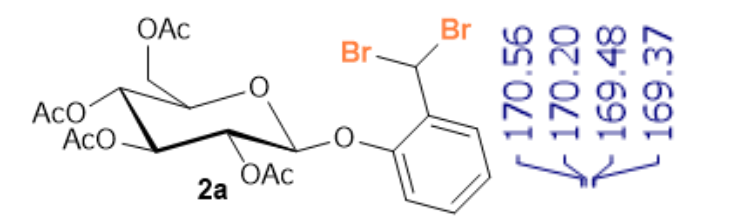

음

\%

m.

ทั ㄱํำ

m 윰ำ

${ }^{13} \mathrm{C}\left(100 \mathrm{MHz}, \mathrm{CDCl}_{3}\right)$ 


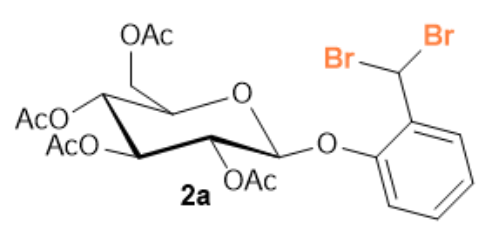

${ }^{1} \mathrm{H}-{ }^{1} \mathrm{H} \operatorname{COSY}$

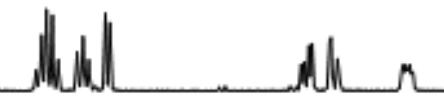

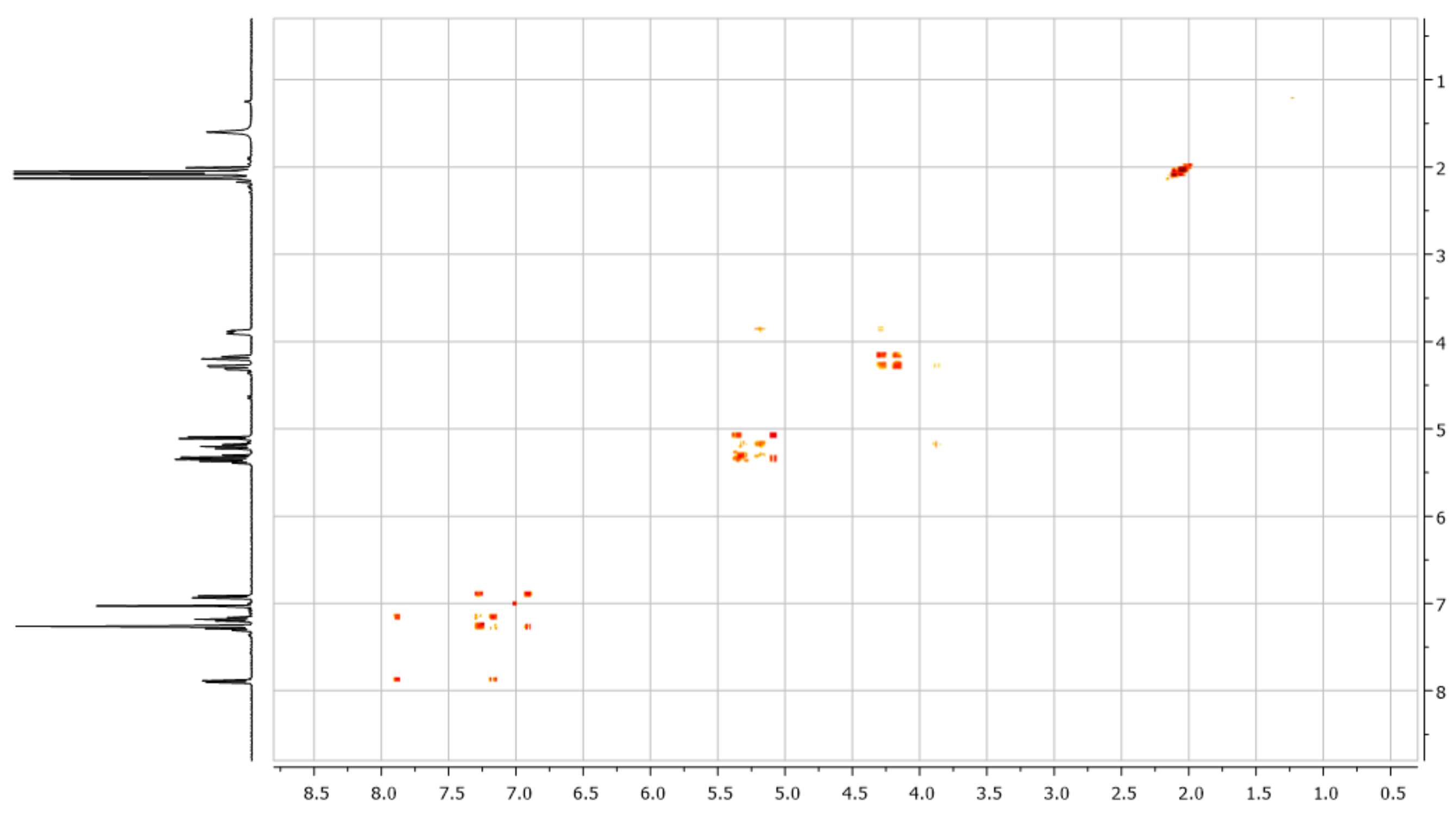


aAC

${ }^{1} \mathrm{H}-{ }^{13} \mathrm{C}$ HSQC

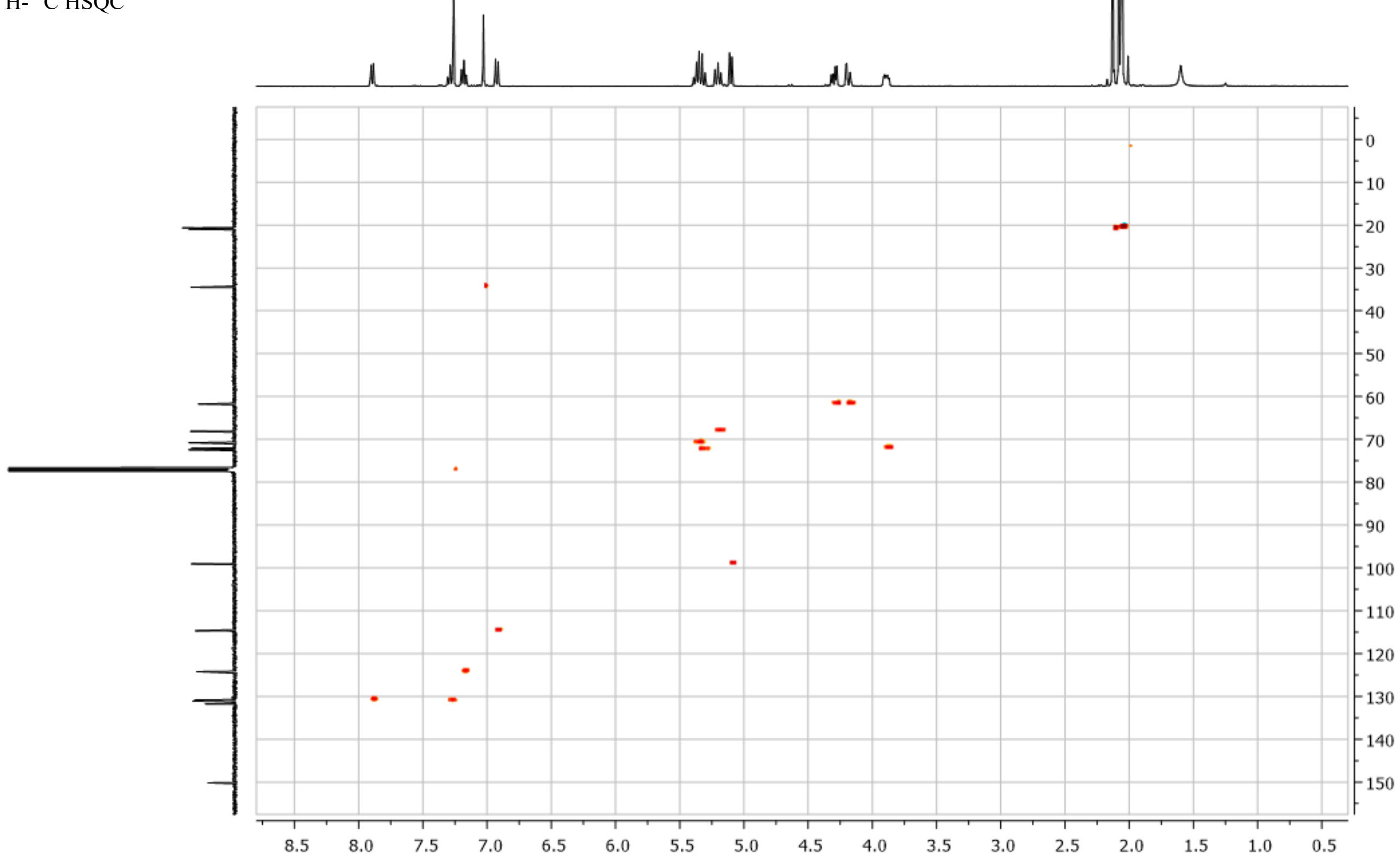




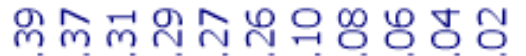

N

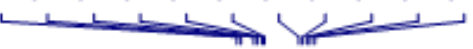

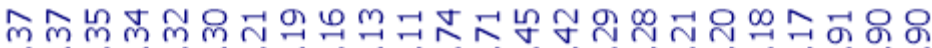

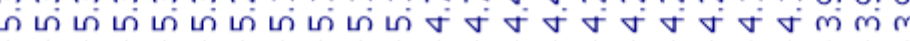

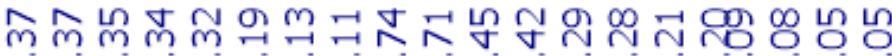

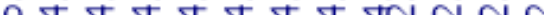

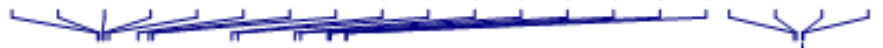

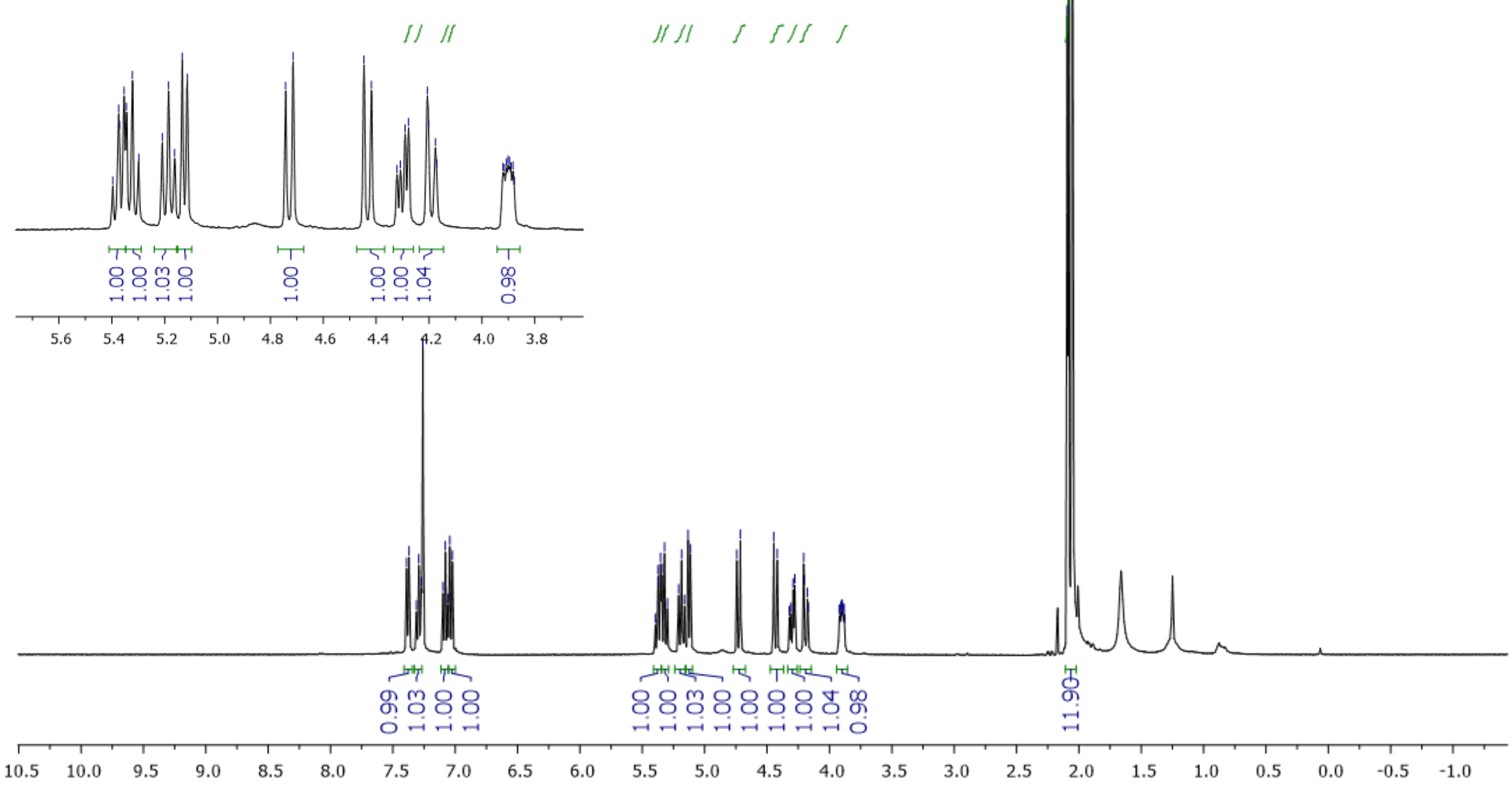




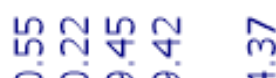

र웜유

$\rightarrow$
ห้ำกำ

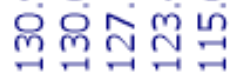

1) $n$
$\infty$
$\infty$
$o$
$o$
1

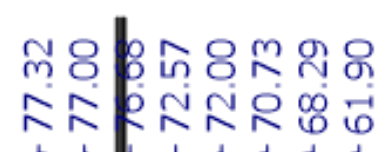


N

क तेंत

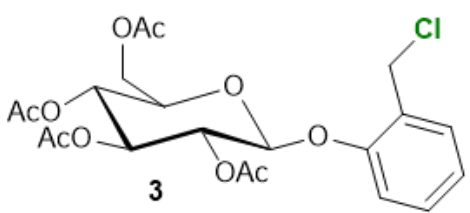

${ }^{13} \mathrm{C}\left(100 \mathrm{MHz}, \mathrm{CDCl}_{3}\right)$ 
(OAC

${ }^{1} \mathrm{H}-{ }^{1} \mathrm{H}$ COSY

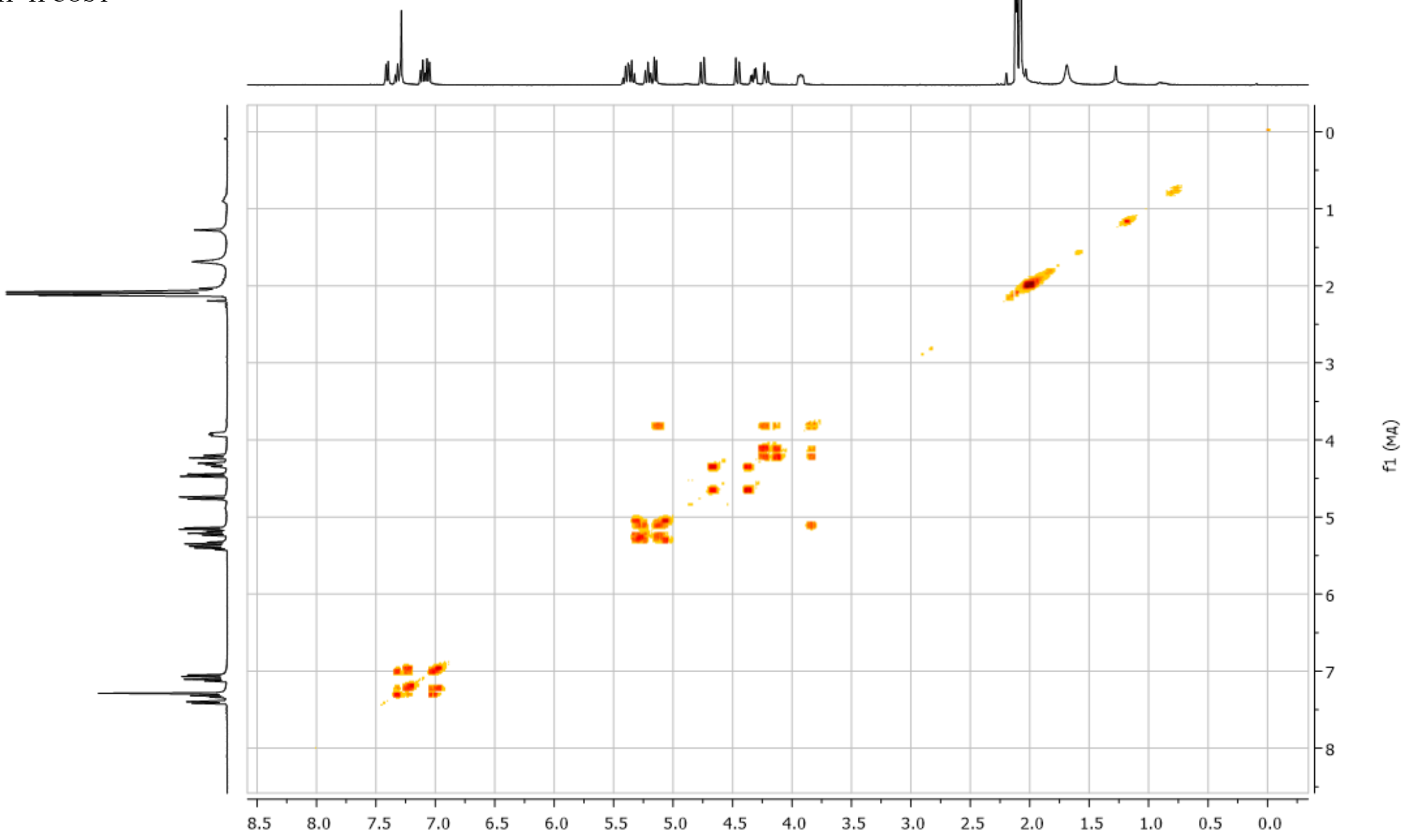




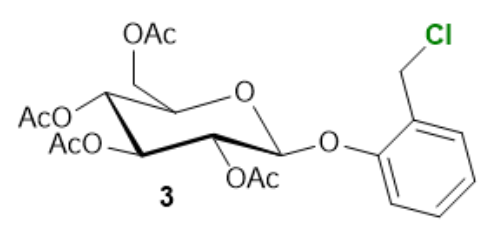

${ }^{1} \mathrm{H}^{-13} \mathrm{C}$ HSQC

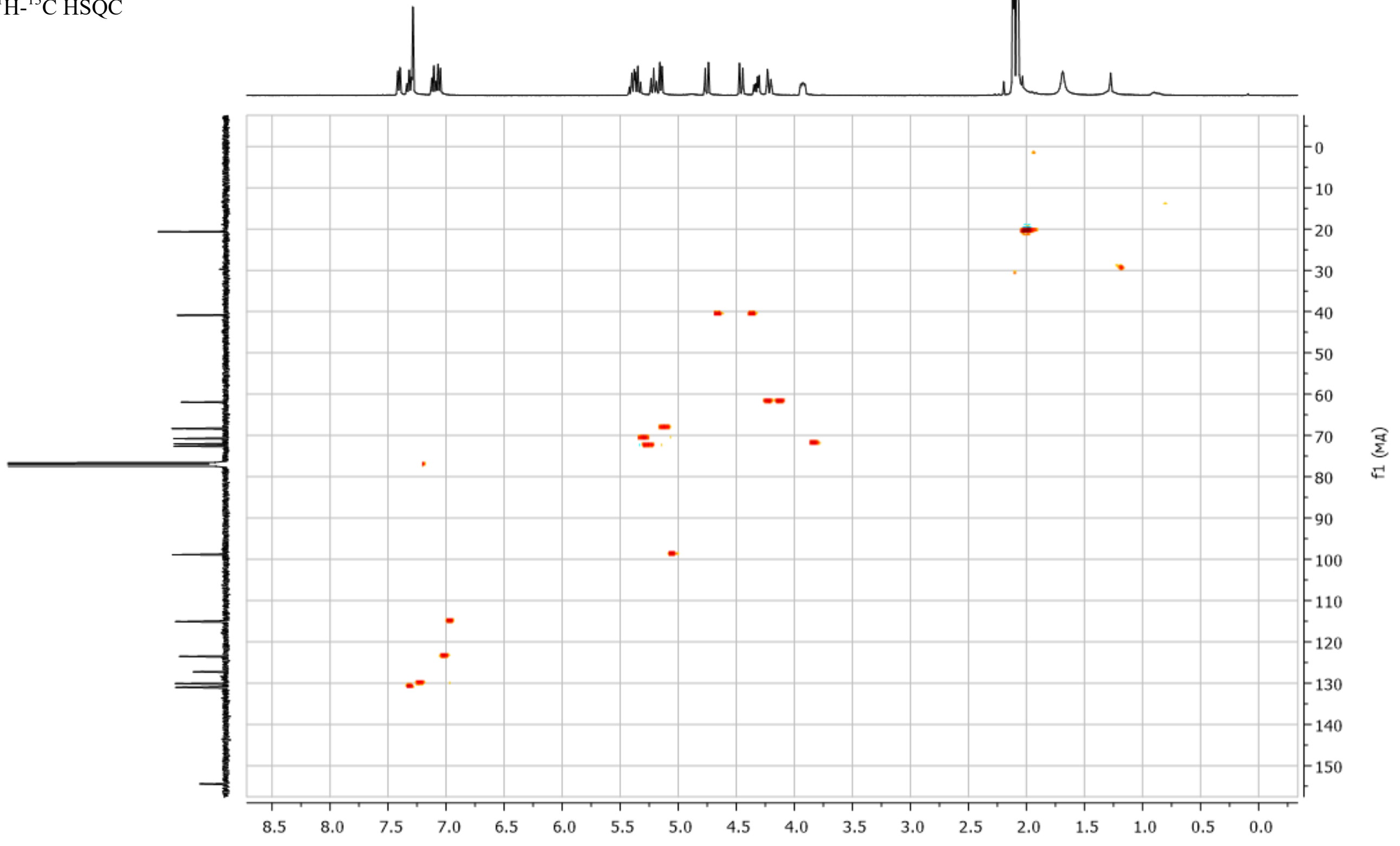




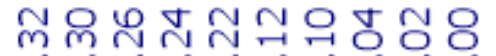
NNNNNNNNN

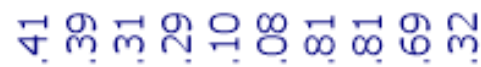
ம

$\longrightarrow$
${ }^{1} \mathrm{H}\left(400 \mathrm{MHz}, \mathrm{DMSO}-d_{6}\right)$

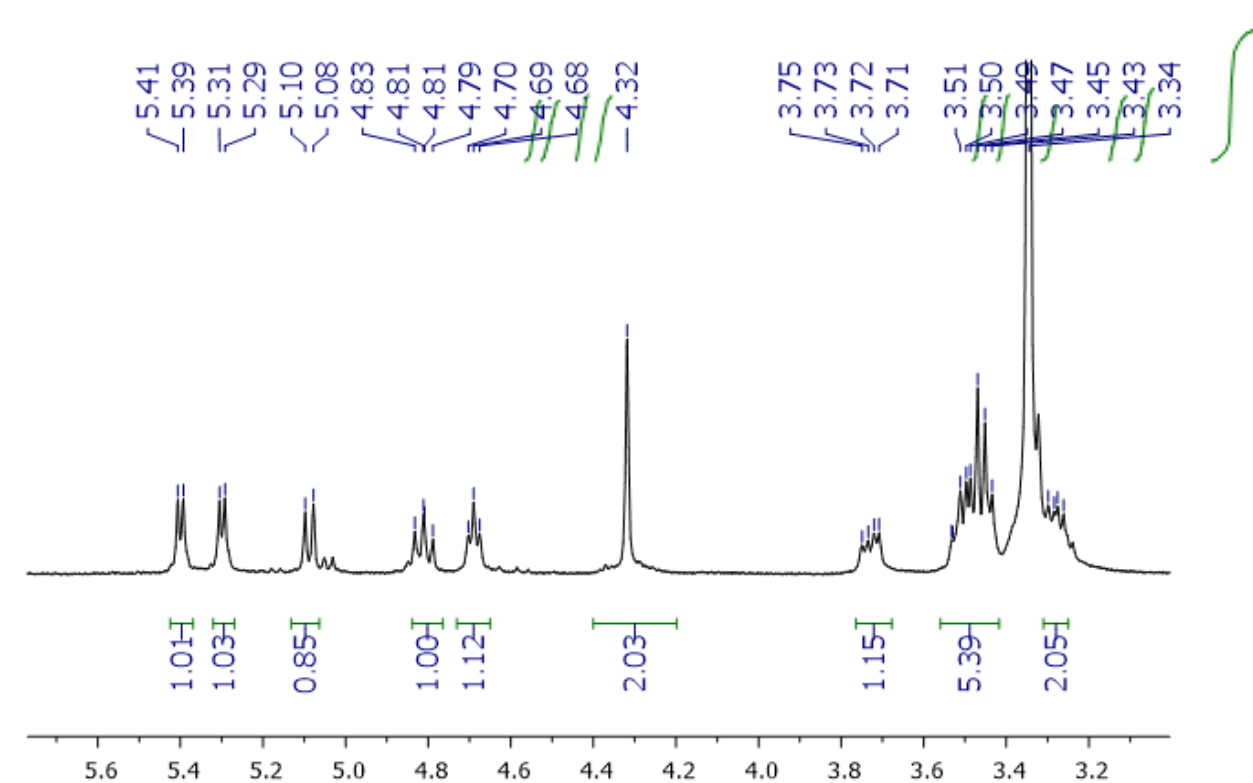

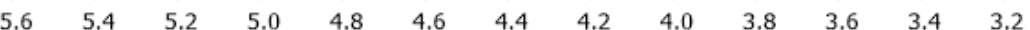

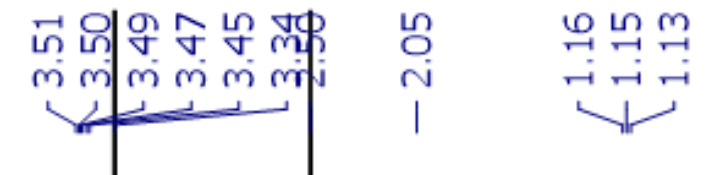

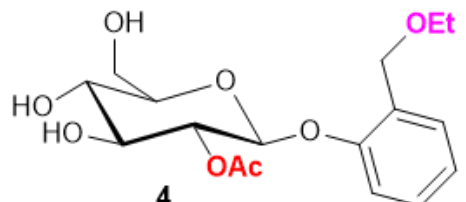

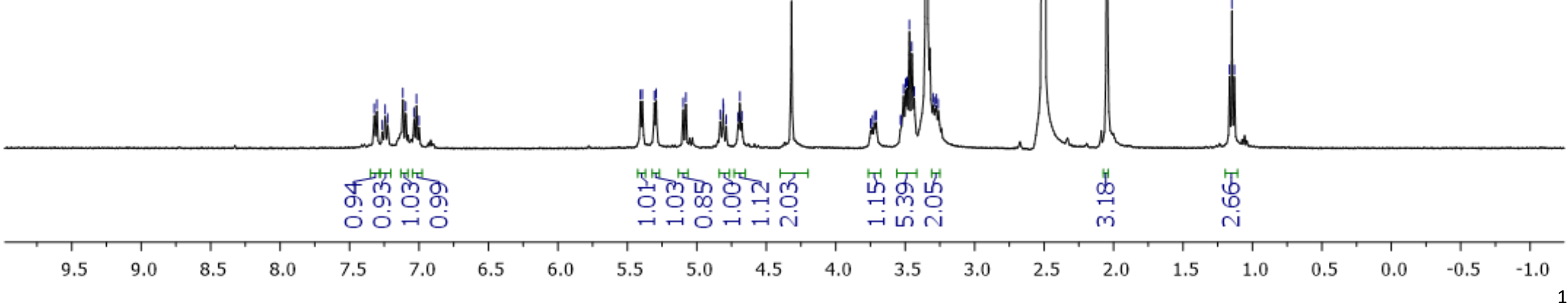




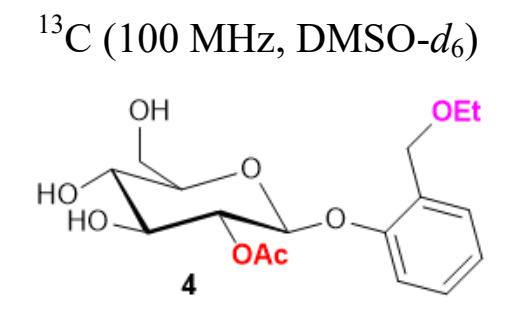

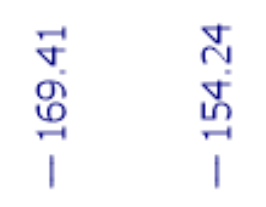

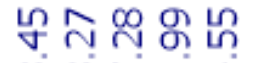

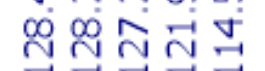

$\underset{\substack{\infty \\ \infty \\ \infty \\ 1}}{1}$

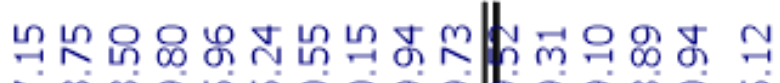

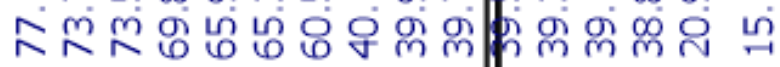

?

ज?

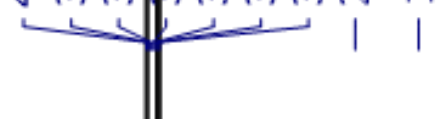

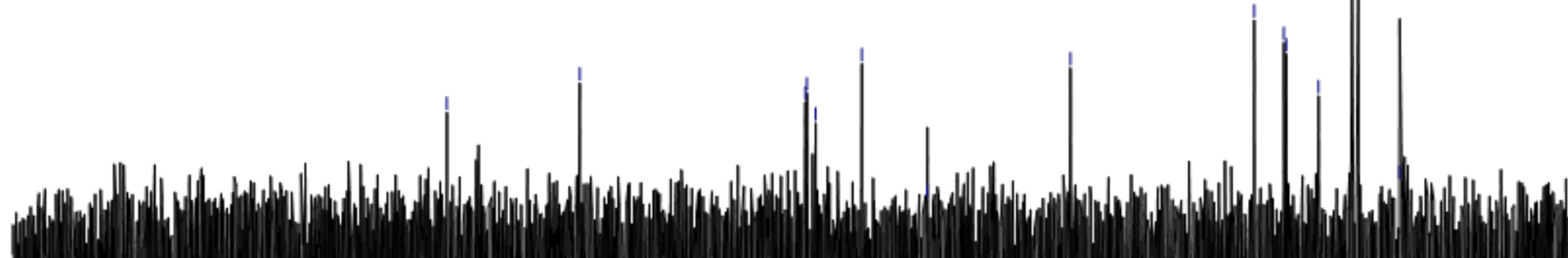

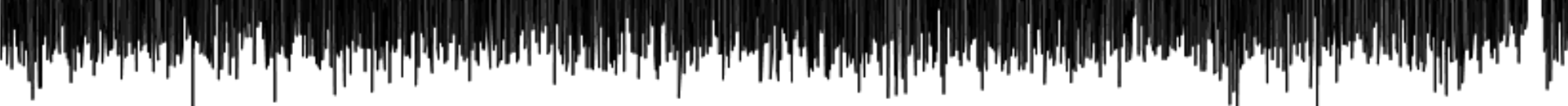

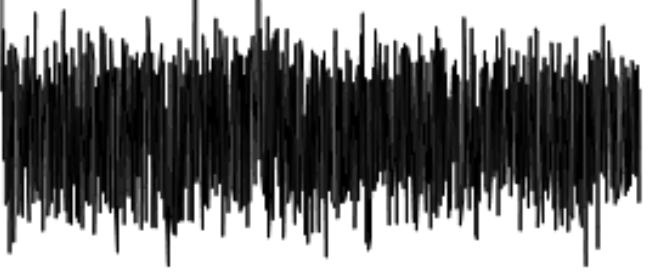


${ }^{1} \mathrm{H}-{ }^{1} \mathrm{H}$ COSY
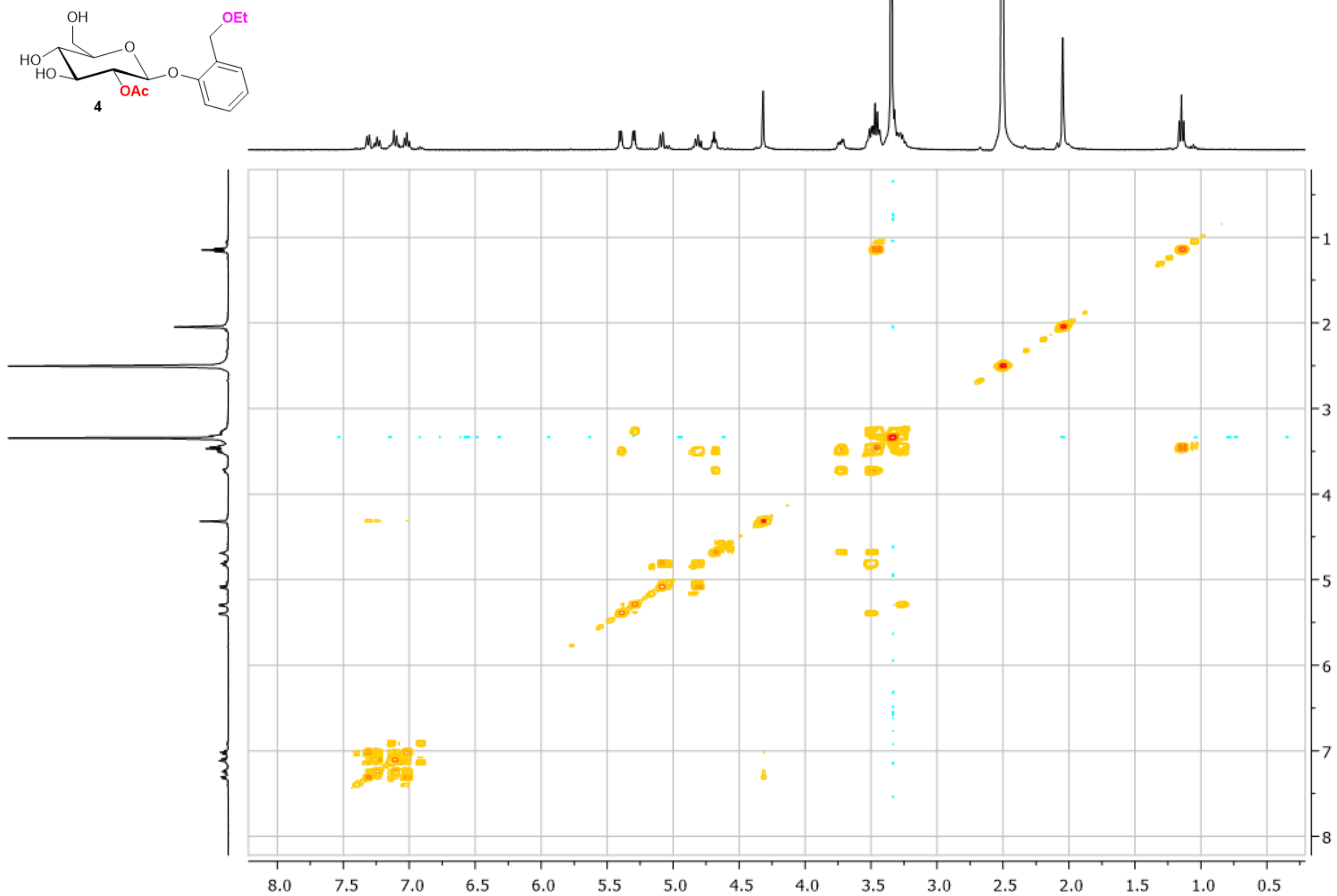
${ }^{1} \mathrm{H}-{ }^{13} \mathrm{C}$ HSQC
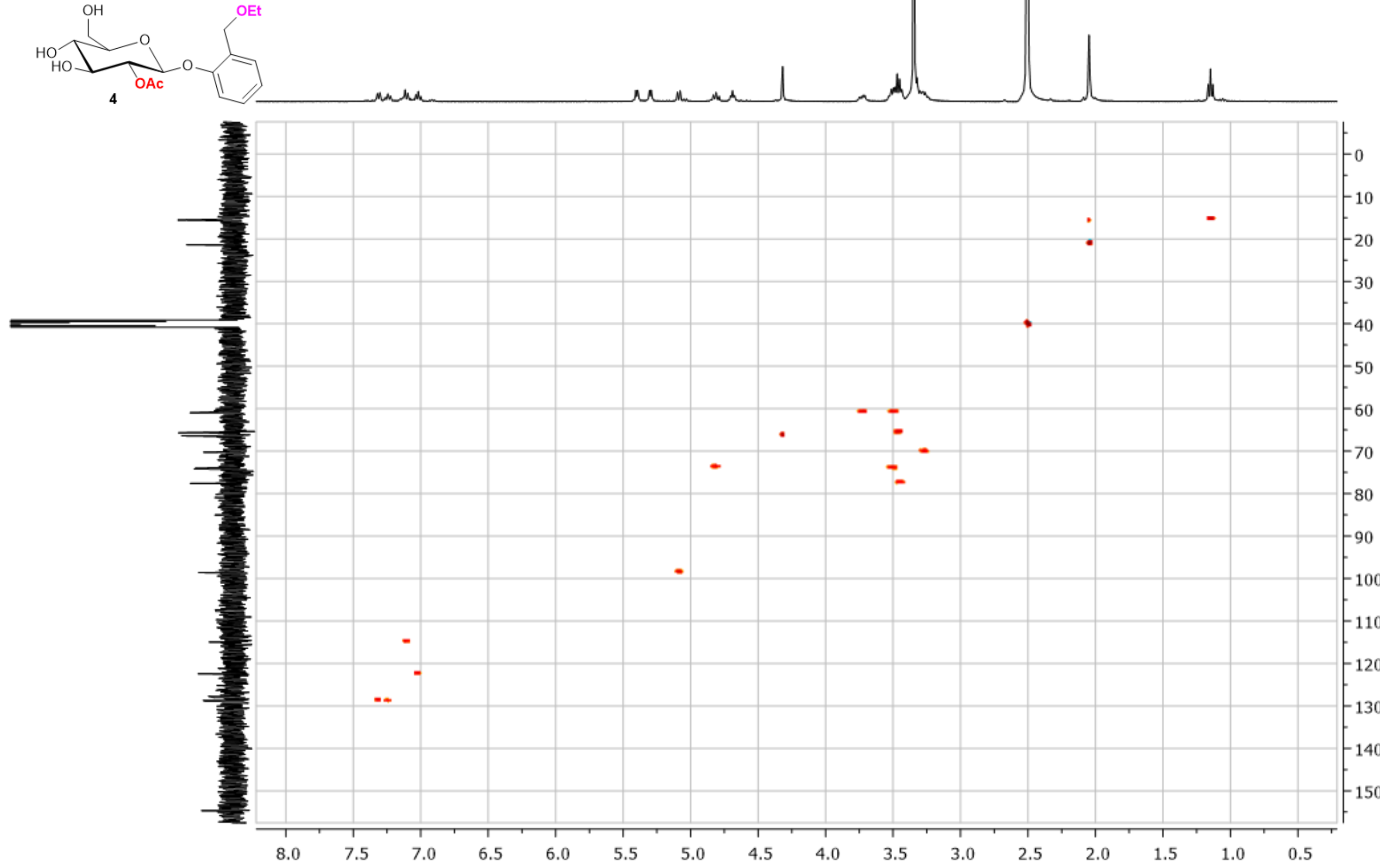
${ }^{1} \mathrm{H}\left(400 \mathrm{MHz}, \mathrm{DMSO}-d_{6}\right)$

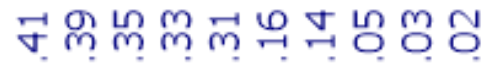
NANNANRNAN 促

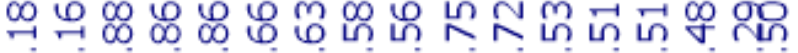

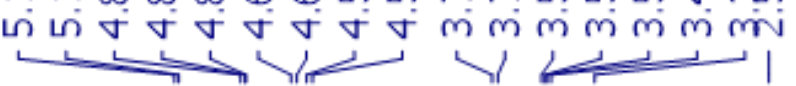

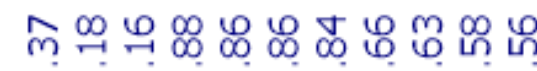

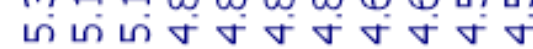

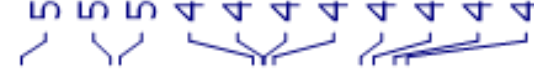

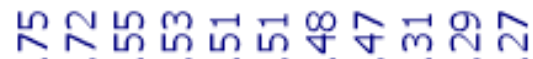

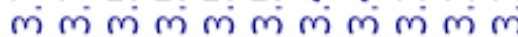
$\iiint$ 난, $/ 11$
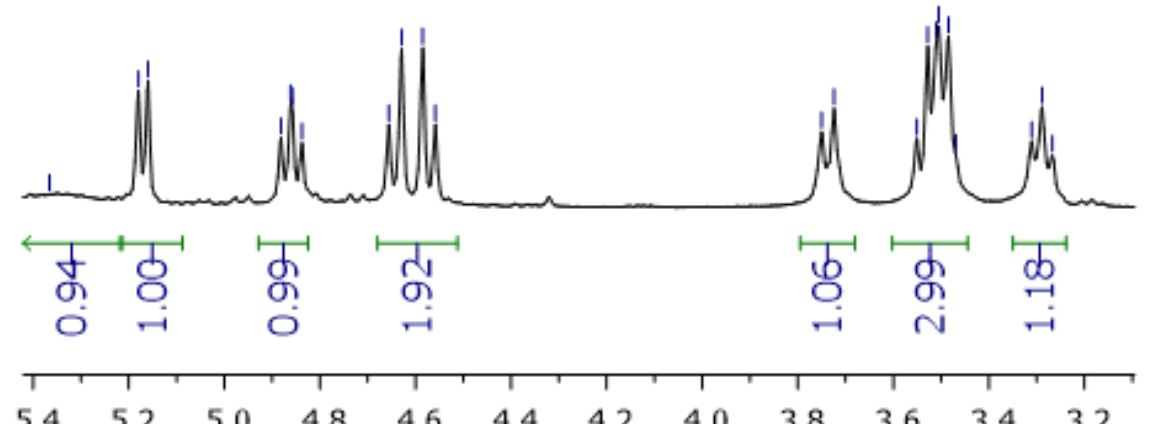

능

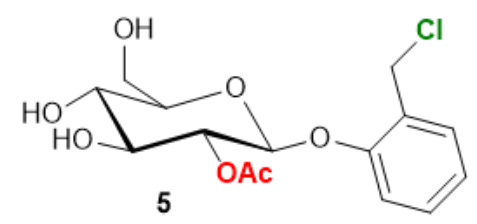

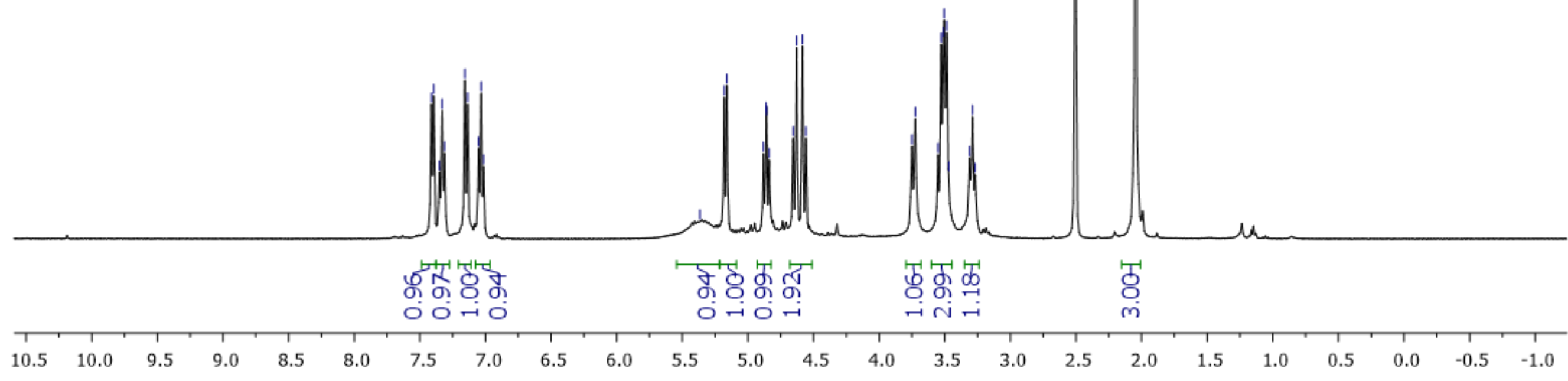


${ }^{13} \mathrm{C}\left(100 \mathrm{MHz}, \mathrm{DMSO}-d_{6}\right)$

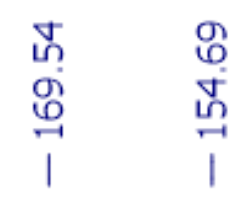

পำ สํำ

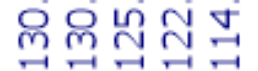

i
เก

ลे

I

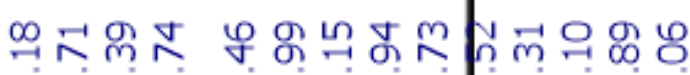

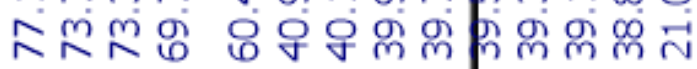
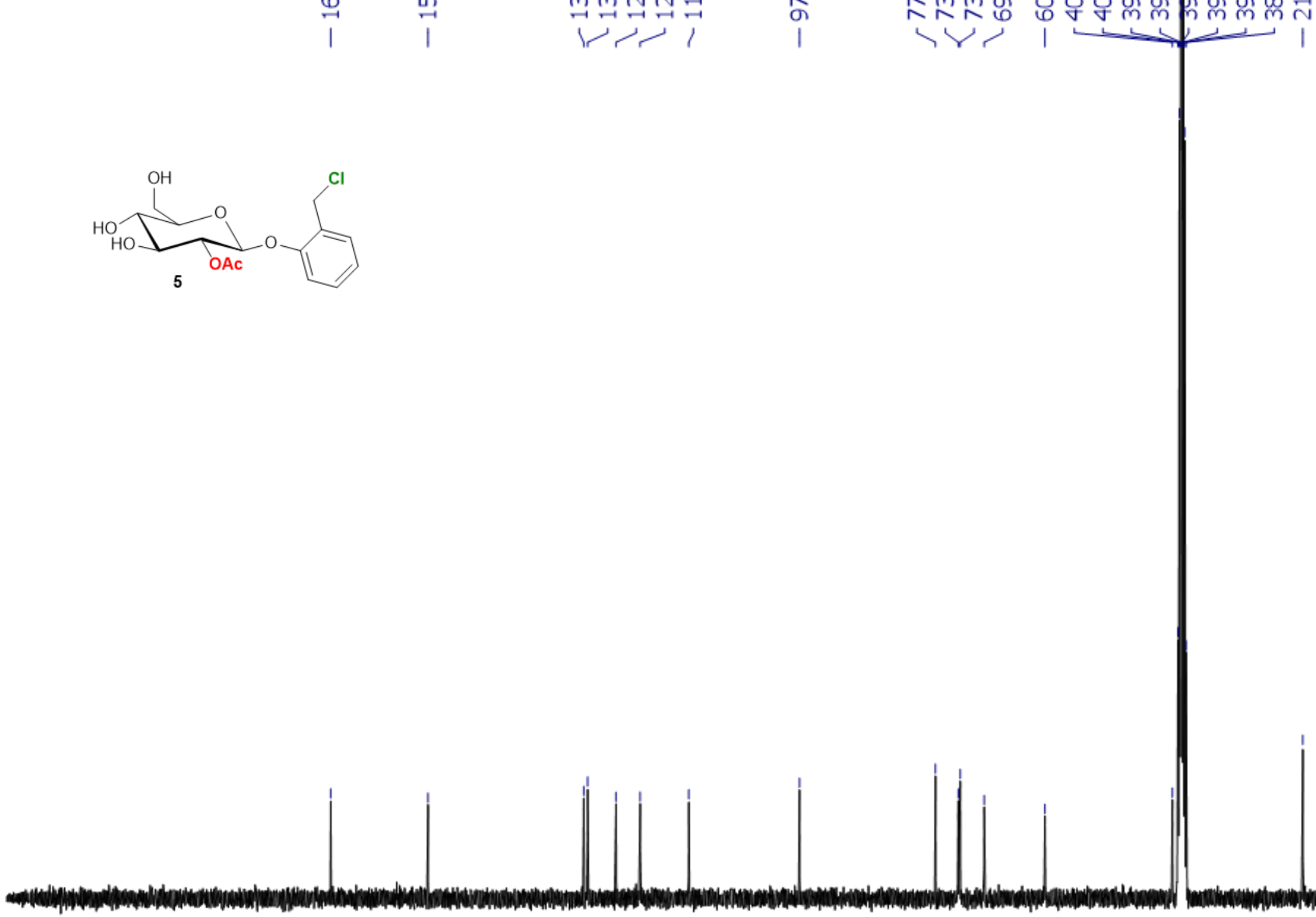


\section{${ }^{1} \mathrm{H}-{ }^{1} \mathrm{H} \operatorname{Cos} \mathrm{Y}$}
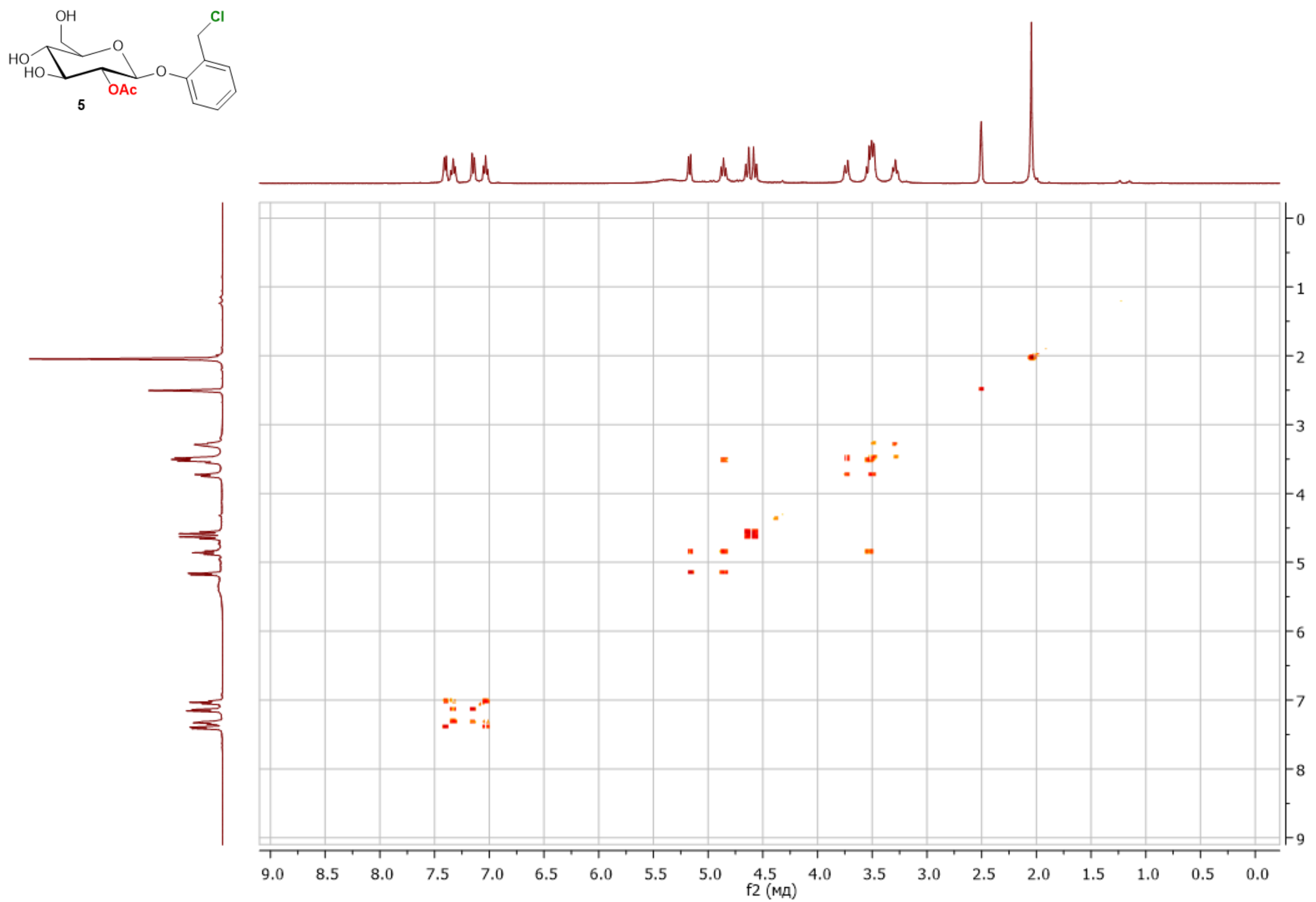
${ }^{1} \mathrm{H}-{ }^{13} \mathrm{C}$ HSQC

OAc

Mu

M

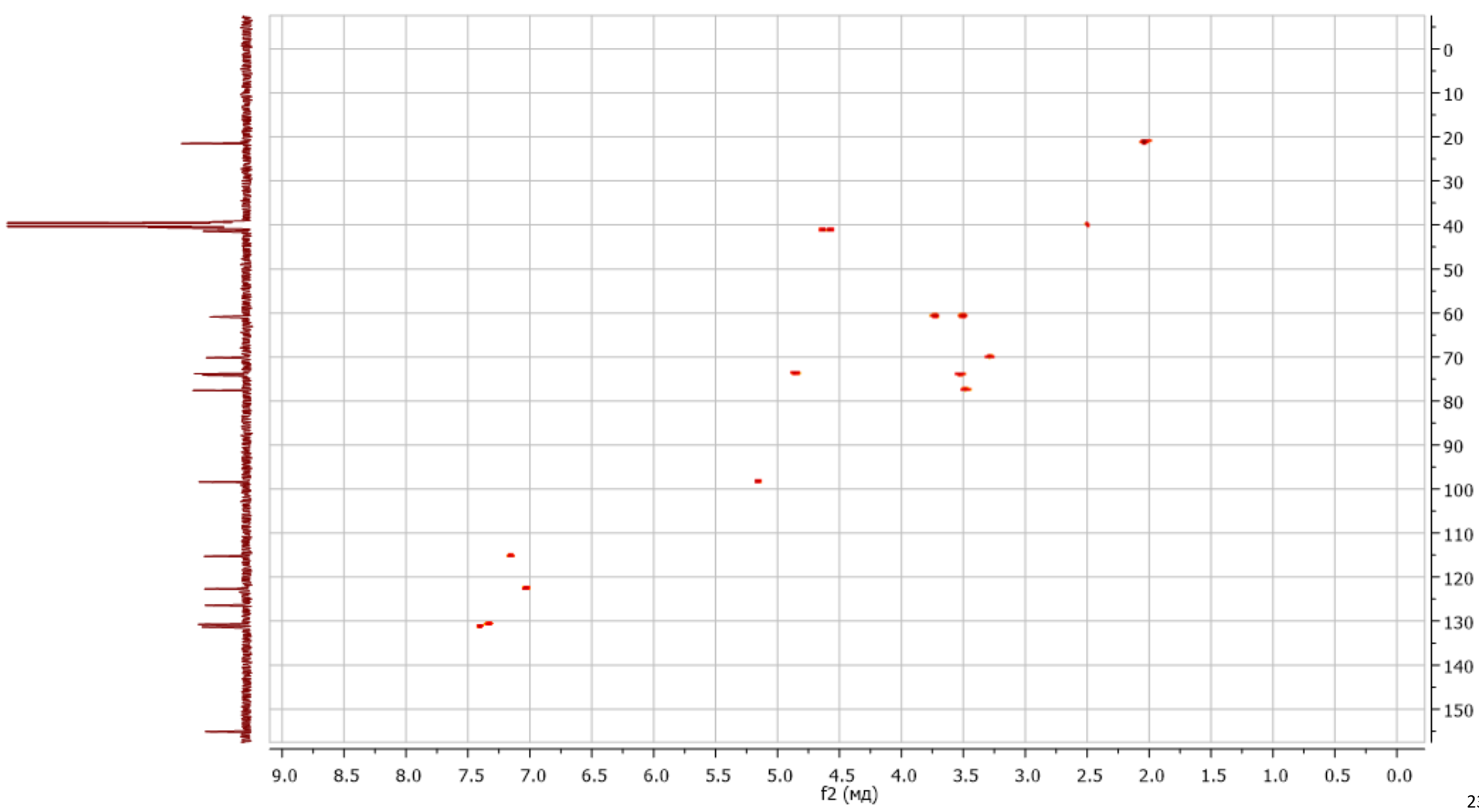


${ }^{1} \mathrm{H}-{ }^{13} \mathrm{C}$ HMBC

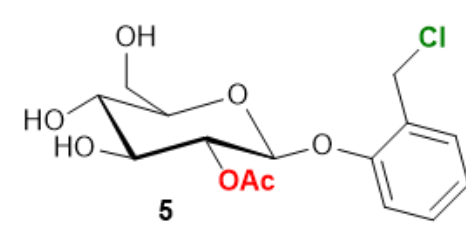

Mu
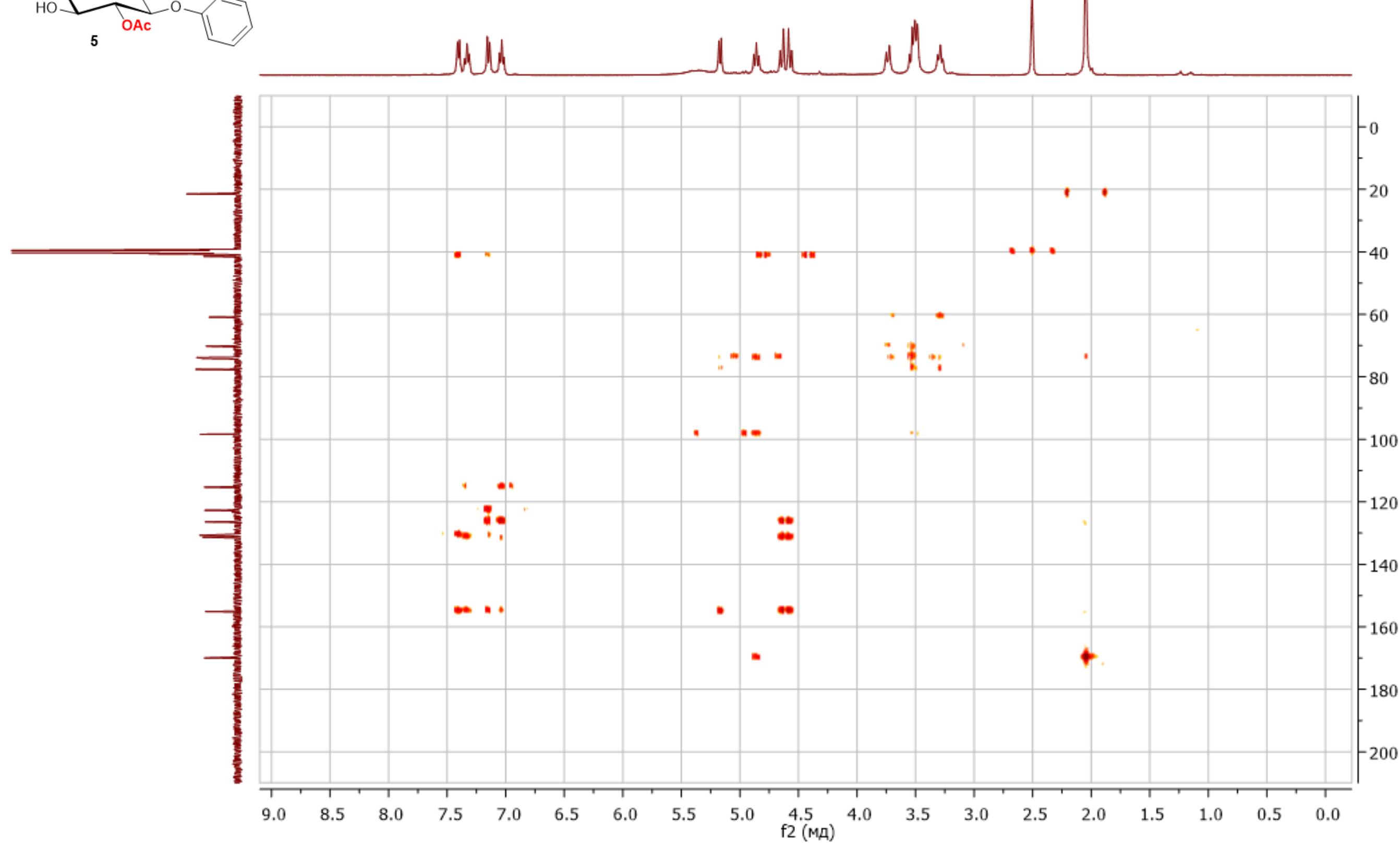


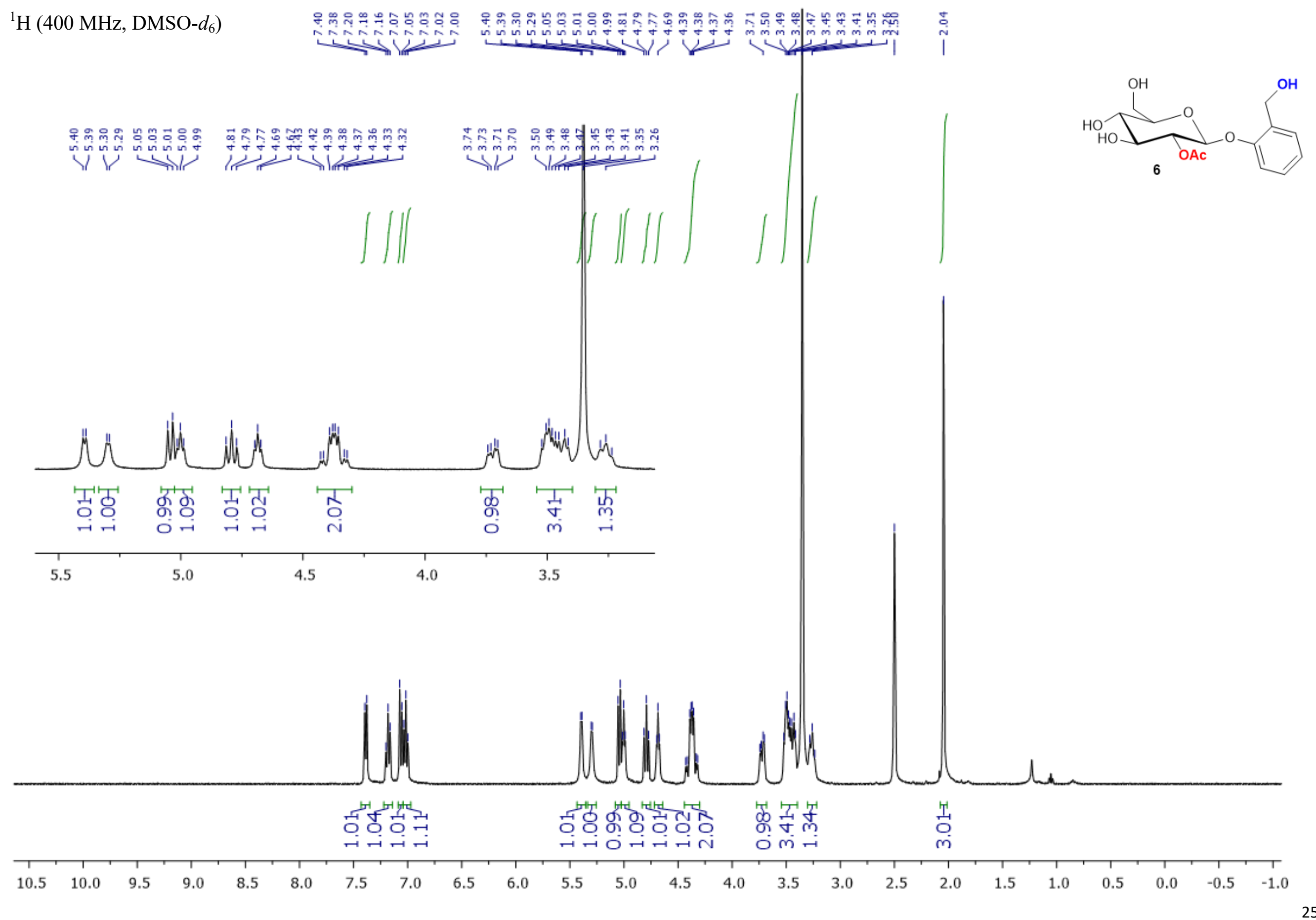


${ }^{13} \mathrm{C}\left(100 \mathrm{MHz}, \mathrm{DMSO}-d_{6}\right)$

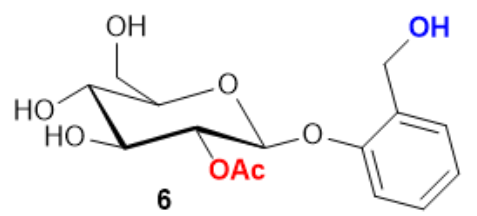




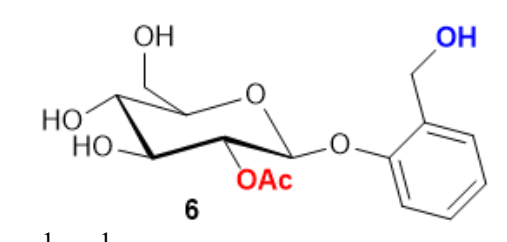

${ }^{1} \mathrm{H}-{ }^{1} \mathrm{H}$ COSY

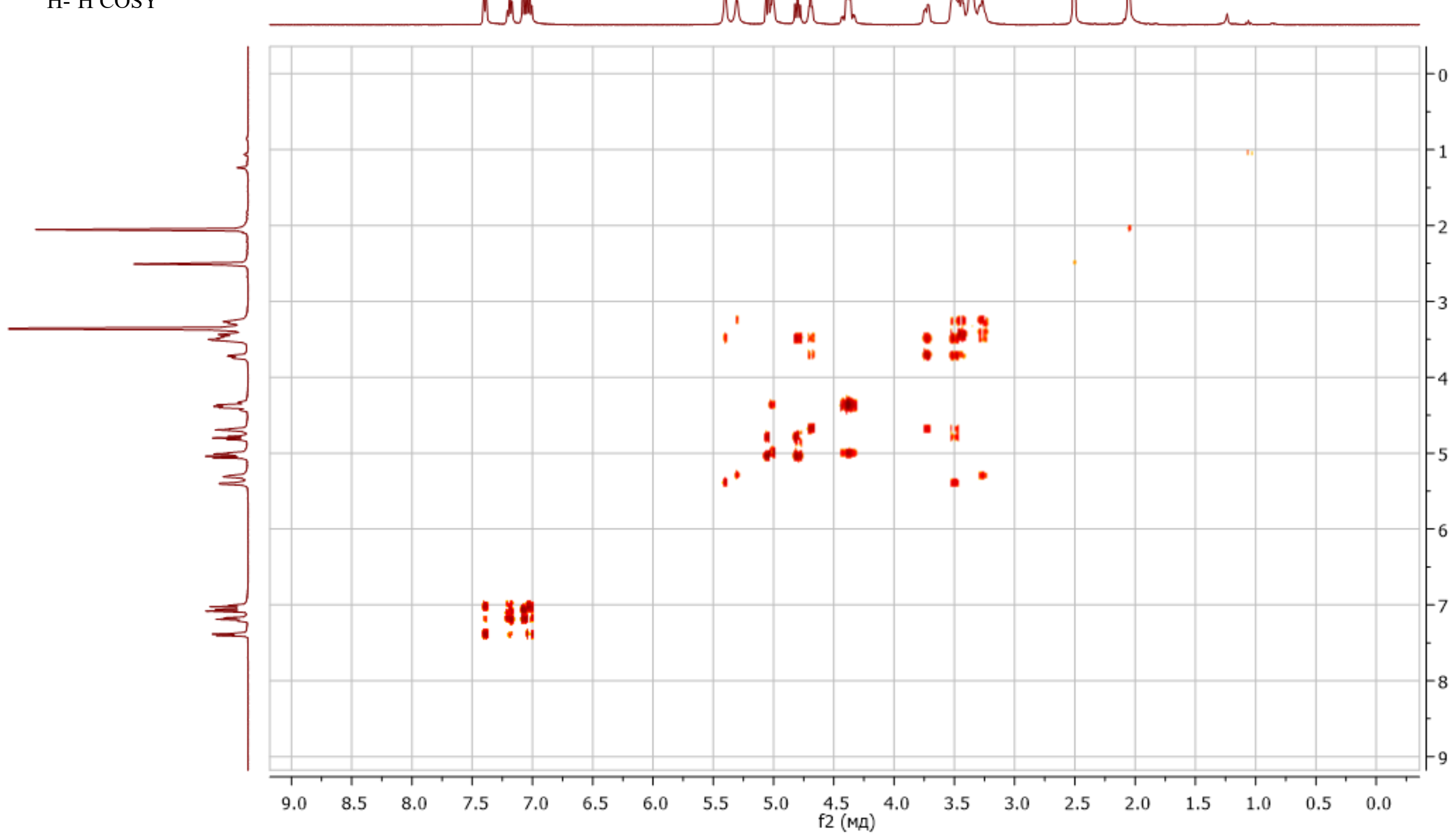


OAc

${ }^{1} \mathrm{H}-{ }^{13} \mathrm{C}$ HSQC

wh

whore wh 


${ }^{1} \mathrm{H}-{ }^{13} \mathrm{C}$ HMBC

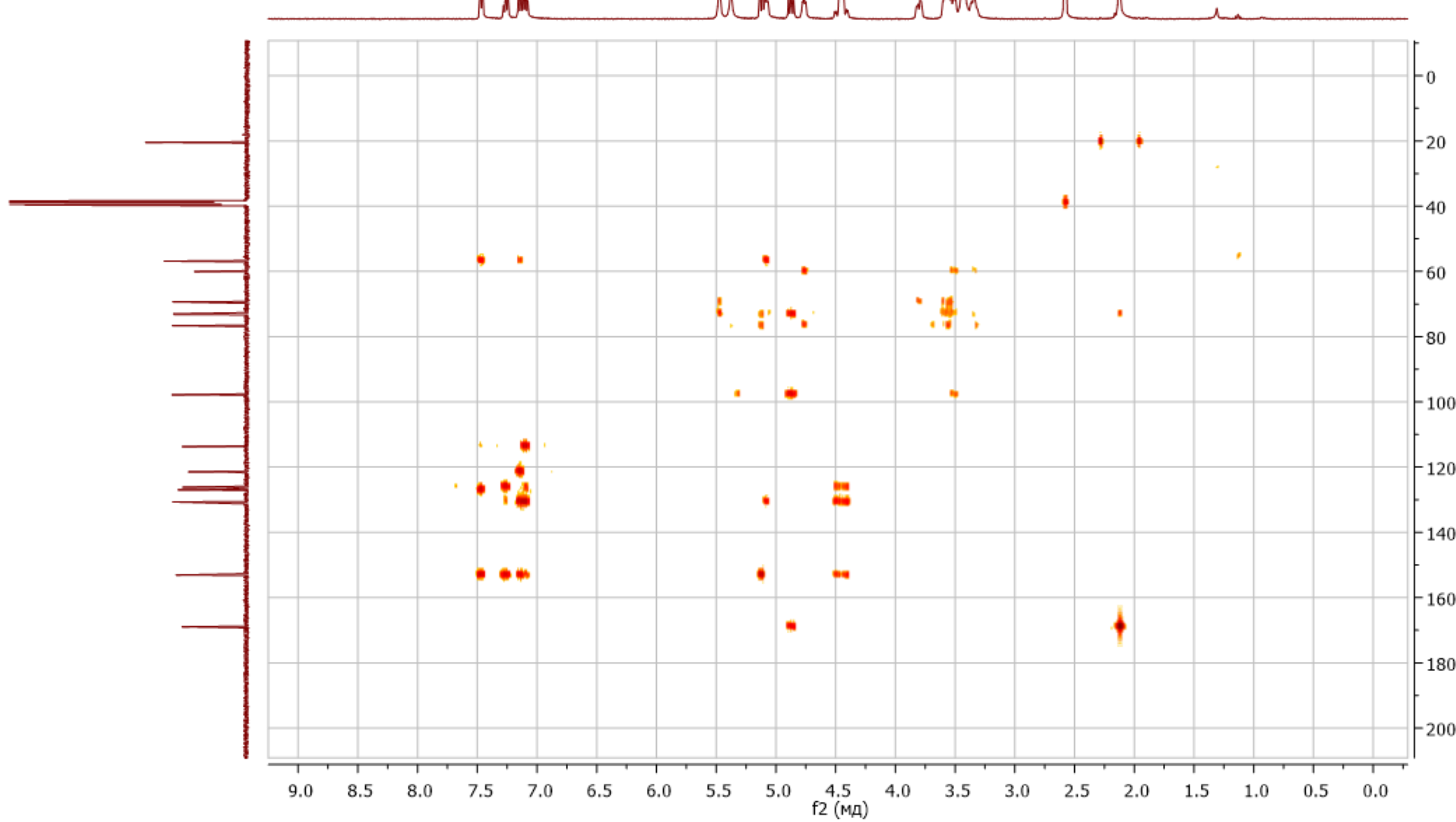


${ }^{1} \mathrm{H}\left(400 \mathrm{MHz}\right.$, DMSO- $\left.d_{6}\right)$

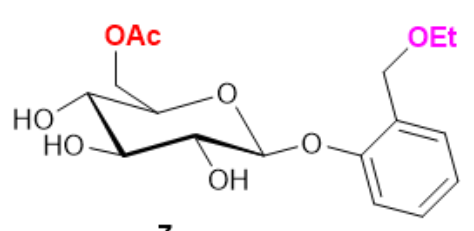

7

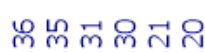

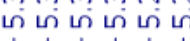
I) i

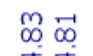

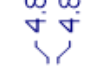

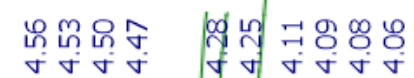

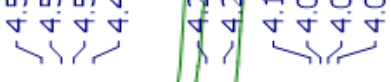

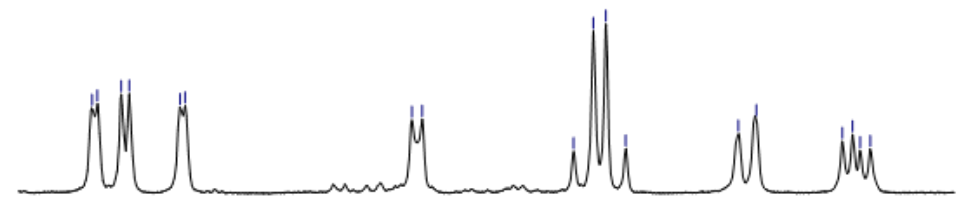

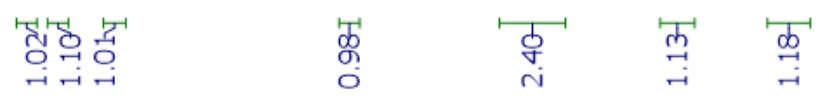

$\begin{array}{lllllllllllllll}5.4 & 5.3 & 5.2 & 5.1 & 5.0 & 4.9 & 4.8 & 4.7 & 4.6 & 4.5 & 4.4 & 4.3 & 4.2 & 4.1 & 4.0\end{array}$

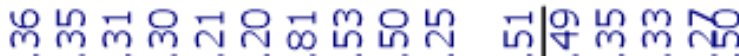
ம

$\longrightarrow$

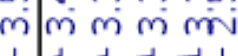

ס

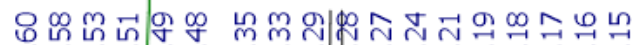
minn 1 प)
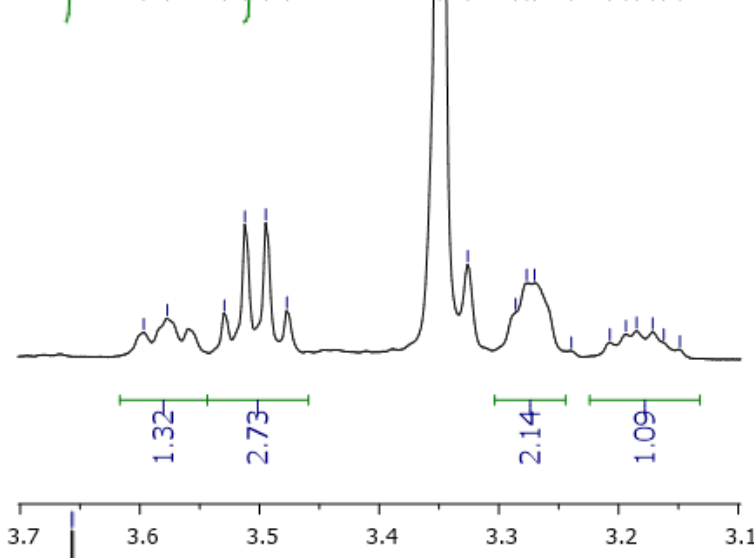

iil

trith

Nㅡㄴ

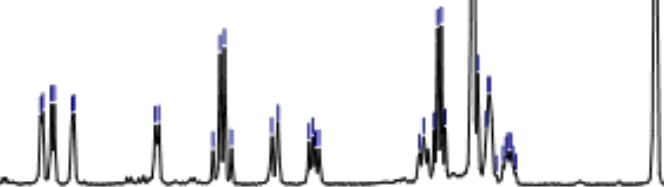

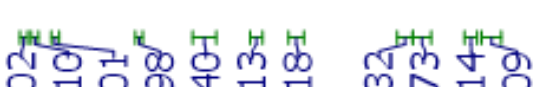

落

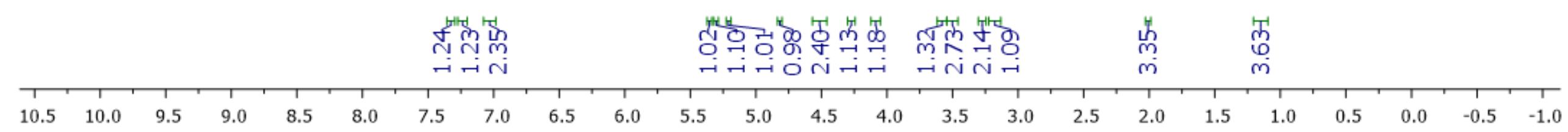


${ }^{13} \mathrm{C}\left(100 \mathrm{MHz}, \mathrm{DMSO}-d_{6}\right)$

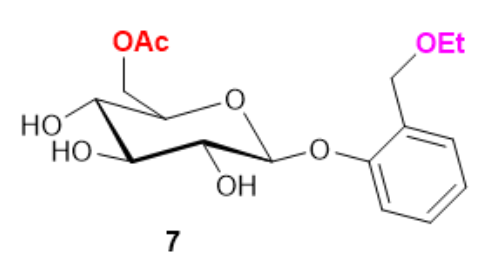

mำ

ำ

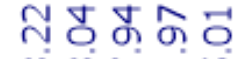

ชูำกำ

w?

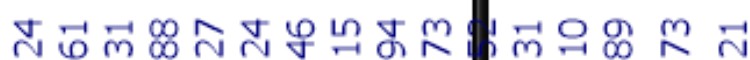

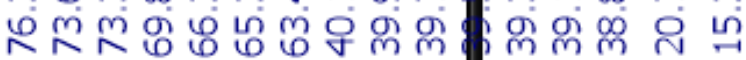

ये।
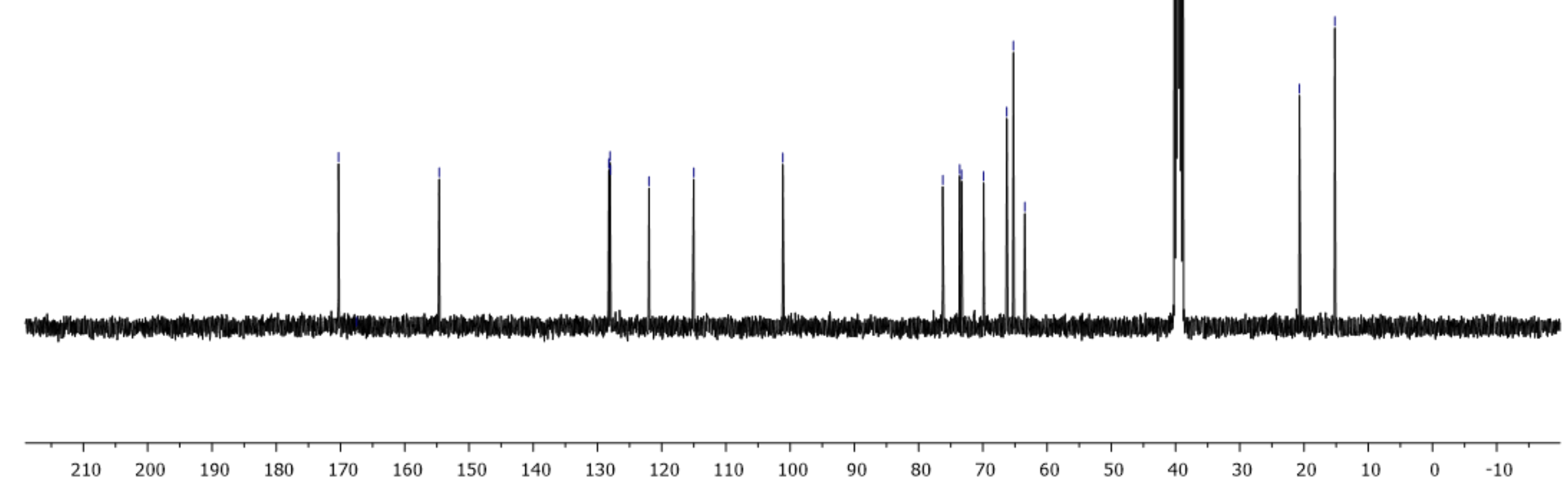
${ }^{1} \mathrm{H}-{ }^{1} \mathrm{H} \mathrm{COSY}$

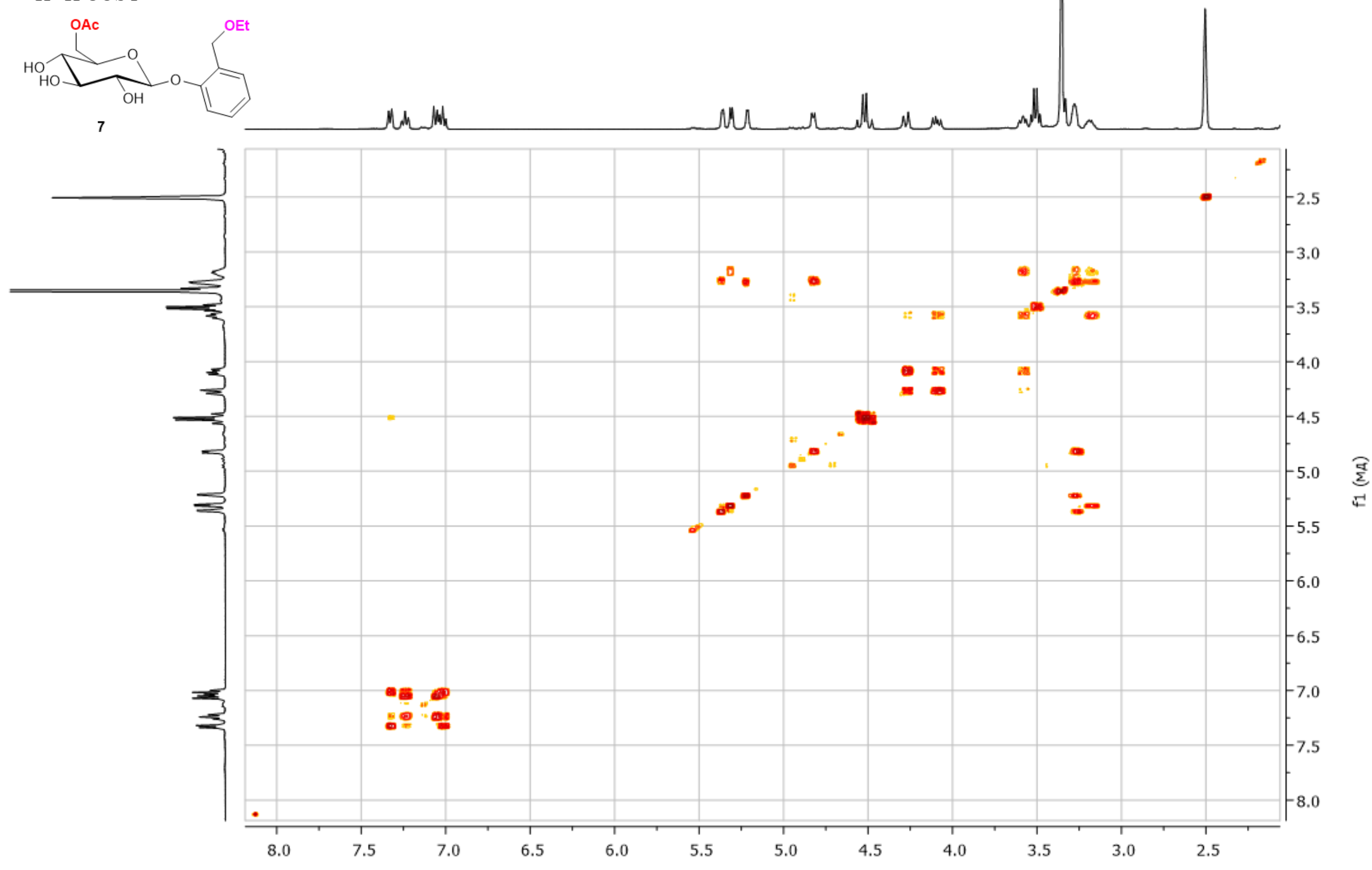


${ }^{1} \mathrm{H}^{-13} \mathrm{C}$ HSQC
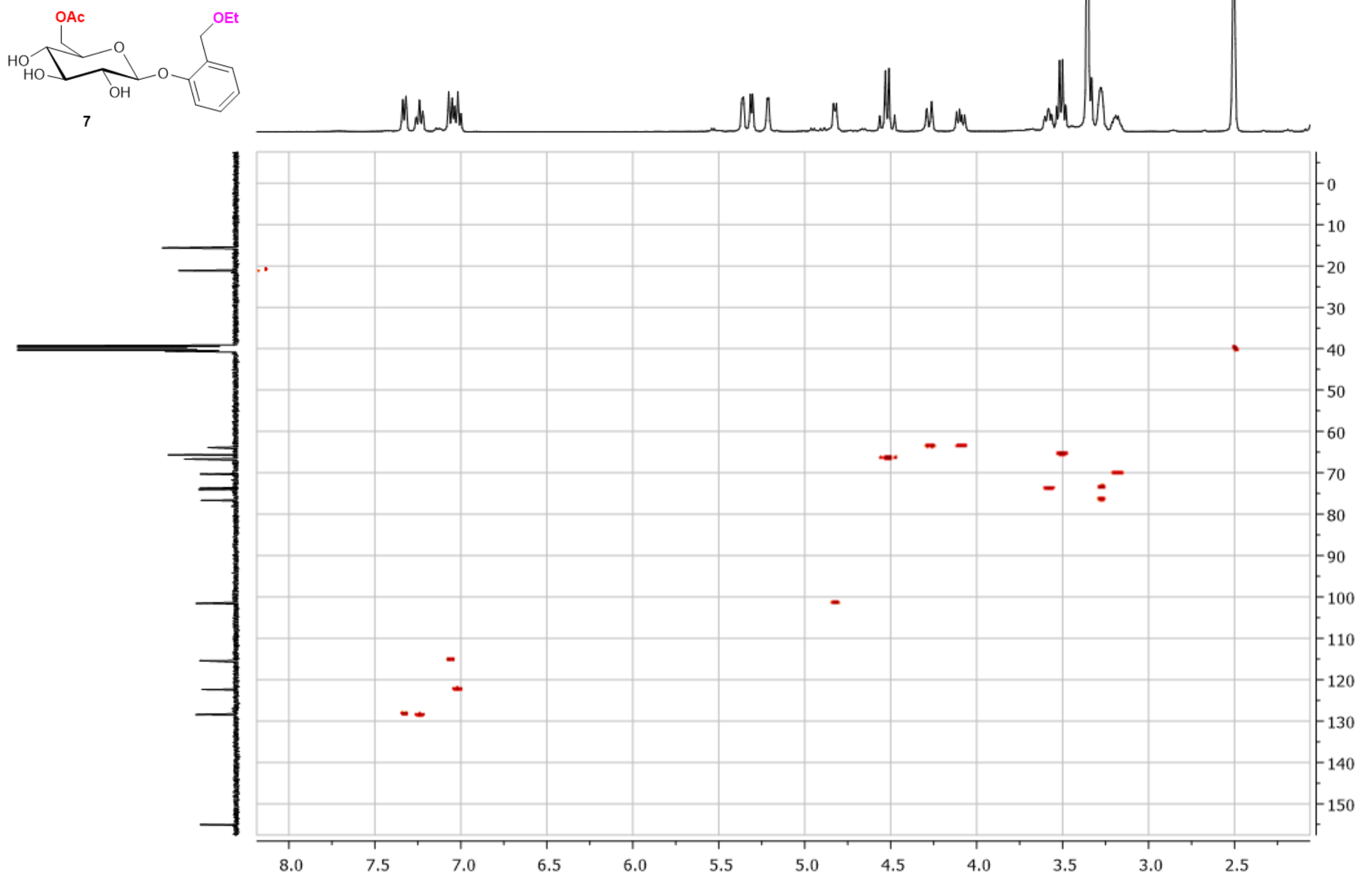


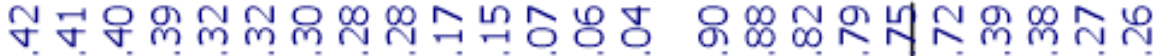
NANNNNANNANNA

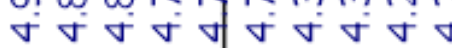
กิ่ мं 1111

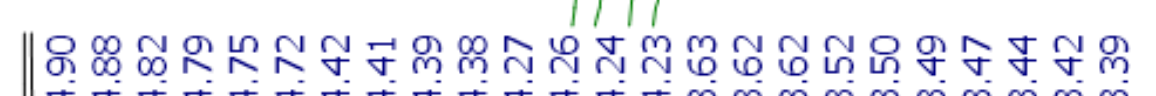
(
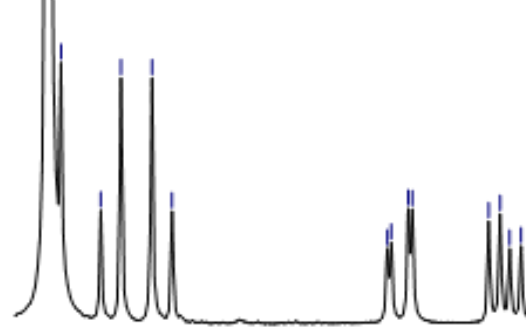

州 क्षे

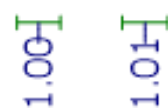

ष्त

4.9

4.7

4.5

4.3

4.1

3.9

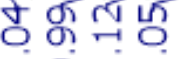
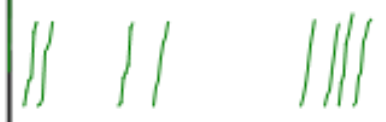

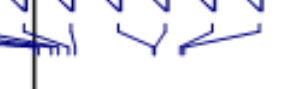

| lill

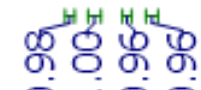

○一
곡

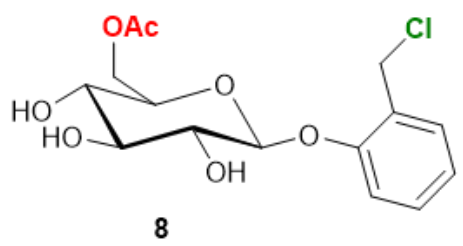

${ }^{1} \mathrm{H}\left(400 \mathrm{MHz}, \mathrm{MeOD}-d_{4}\right)$

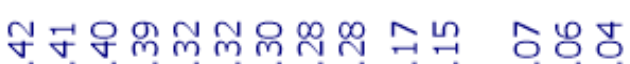

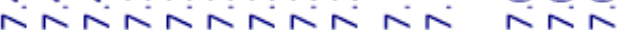

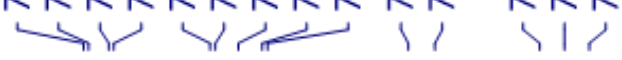

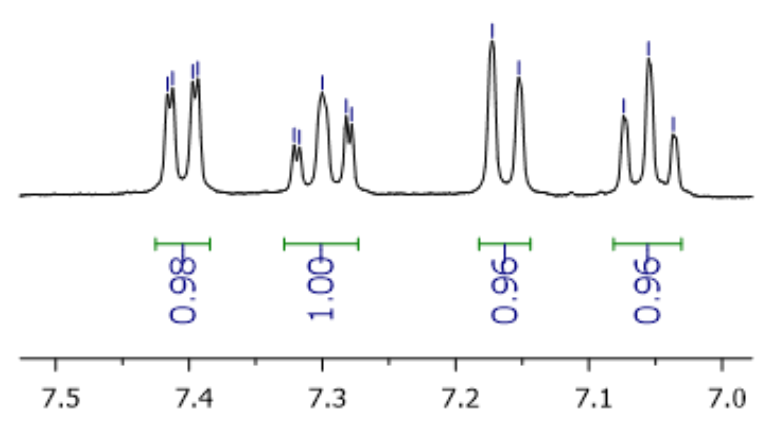




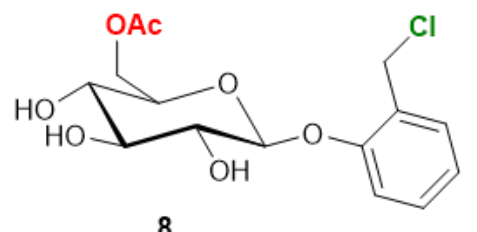

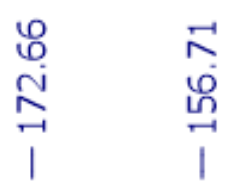

${ }^{13} \mathrm{C}\left(100 \mathrm{MHz}, \mathrm{MeOD}-d_{4}\right)$

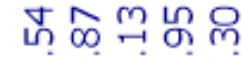

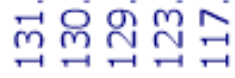

1

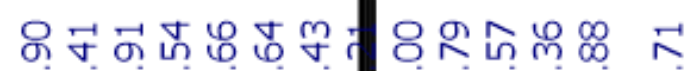

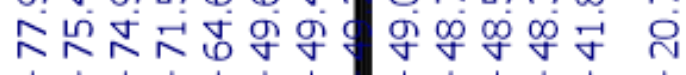

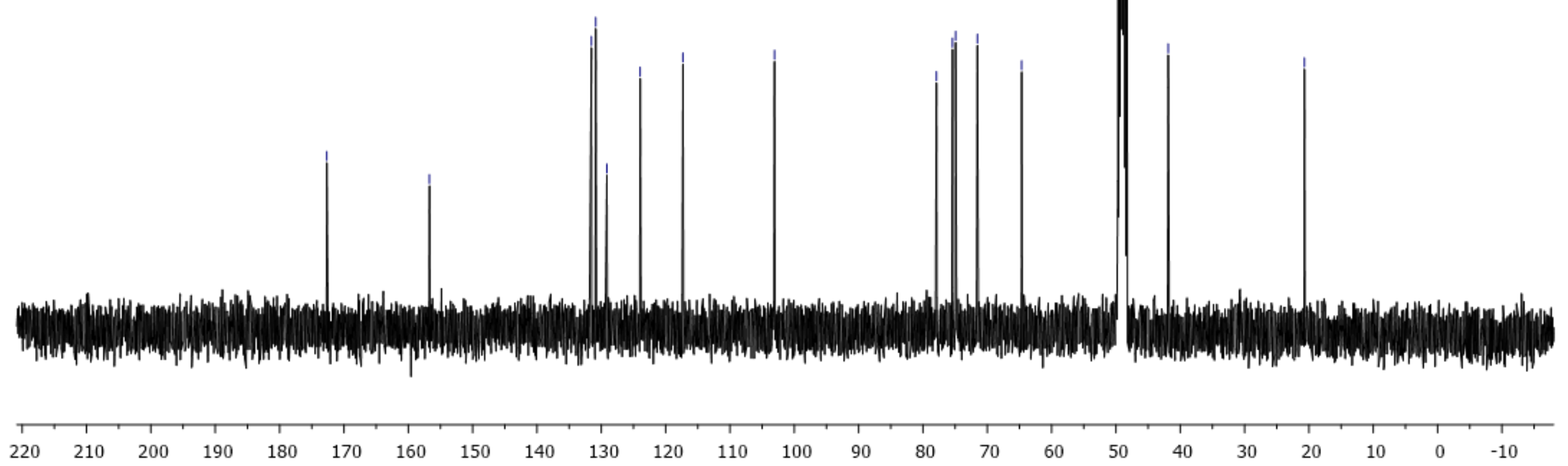




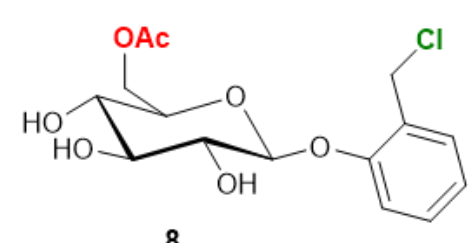

${ }^{1} \mathrm{H}-{ }^{1} \mathrm{H} \mathrm{COSY}$

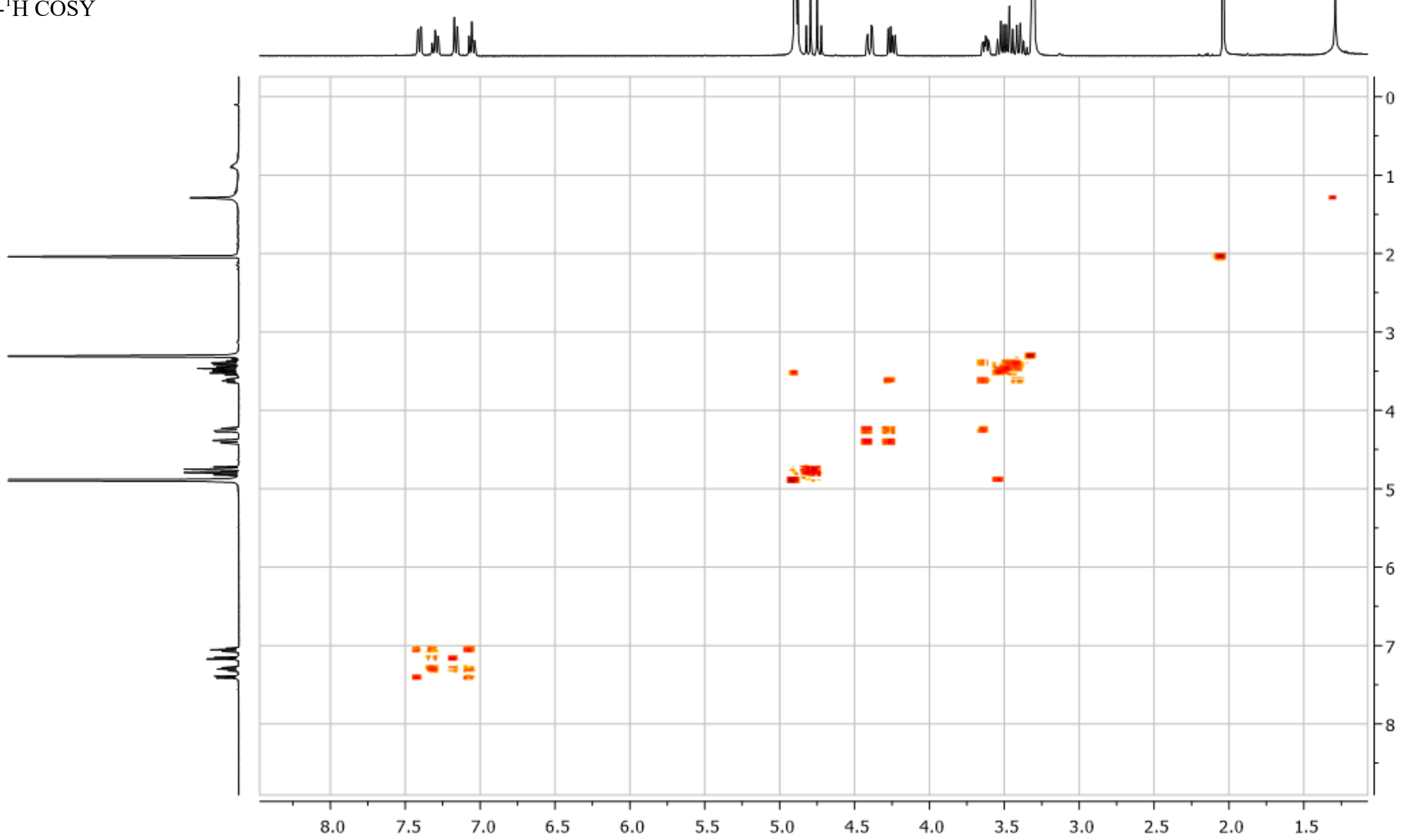




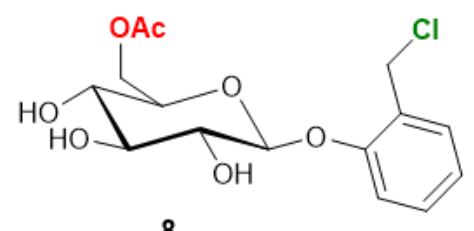

8

${ }^{1} \mathrm{H}-{ }^{13} \mathrm{C}$ HSQC

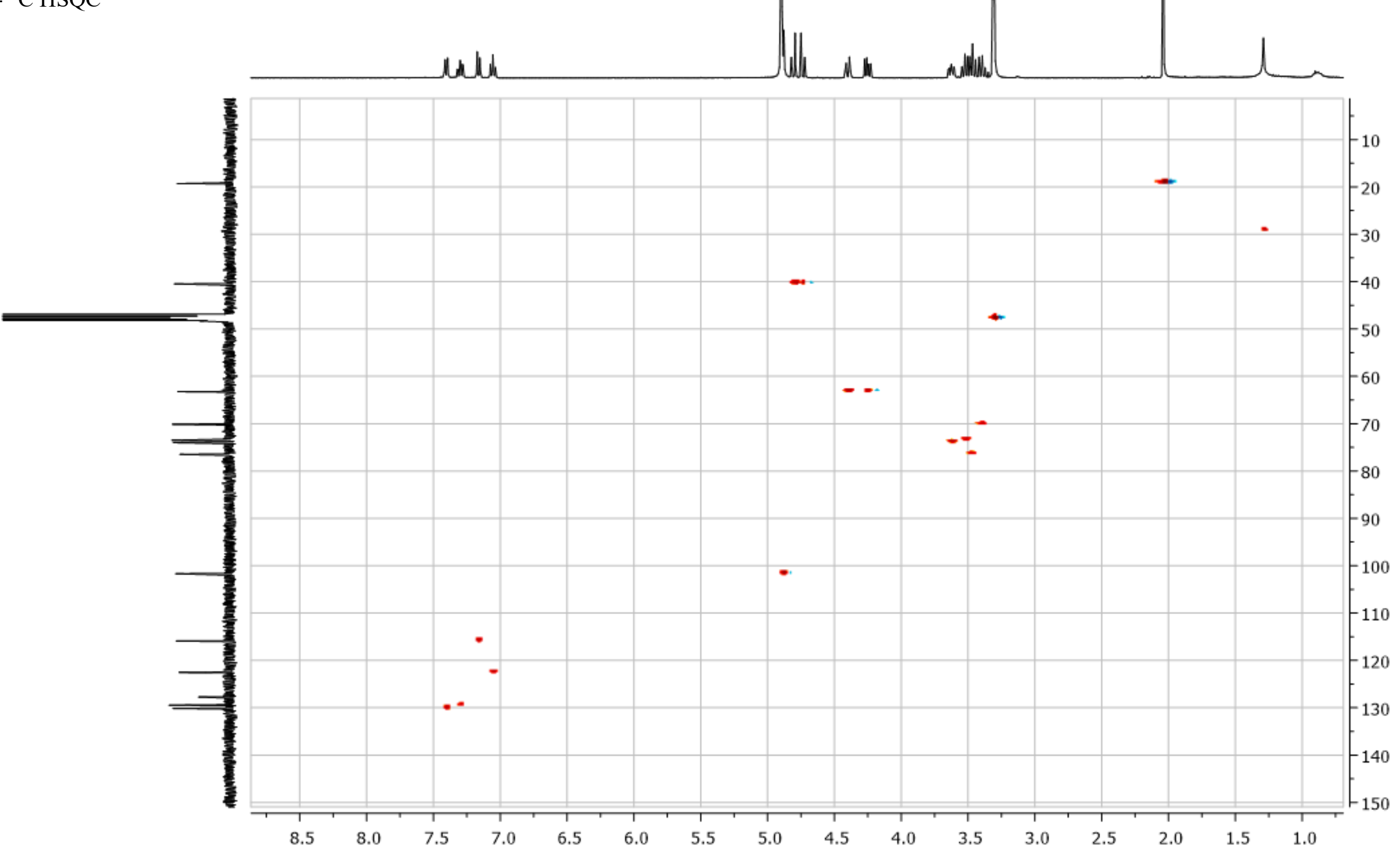


ติ่ NNNNNNNE $\longrightarrow$

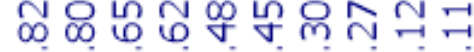

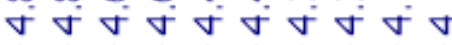
एका ए।

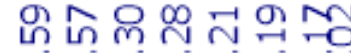
mंm mंm m

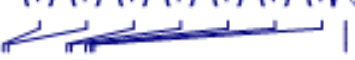

œ

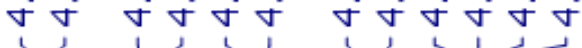
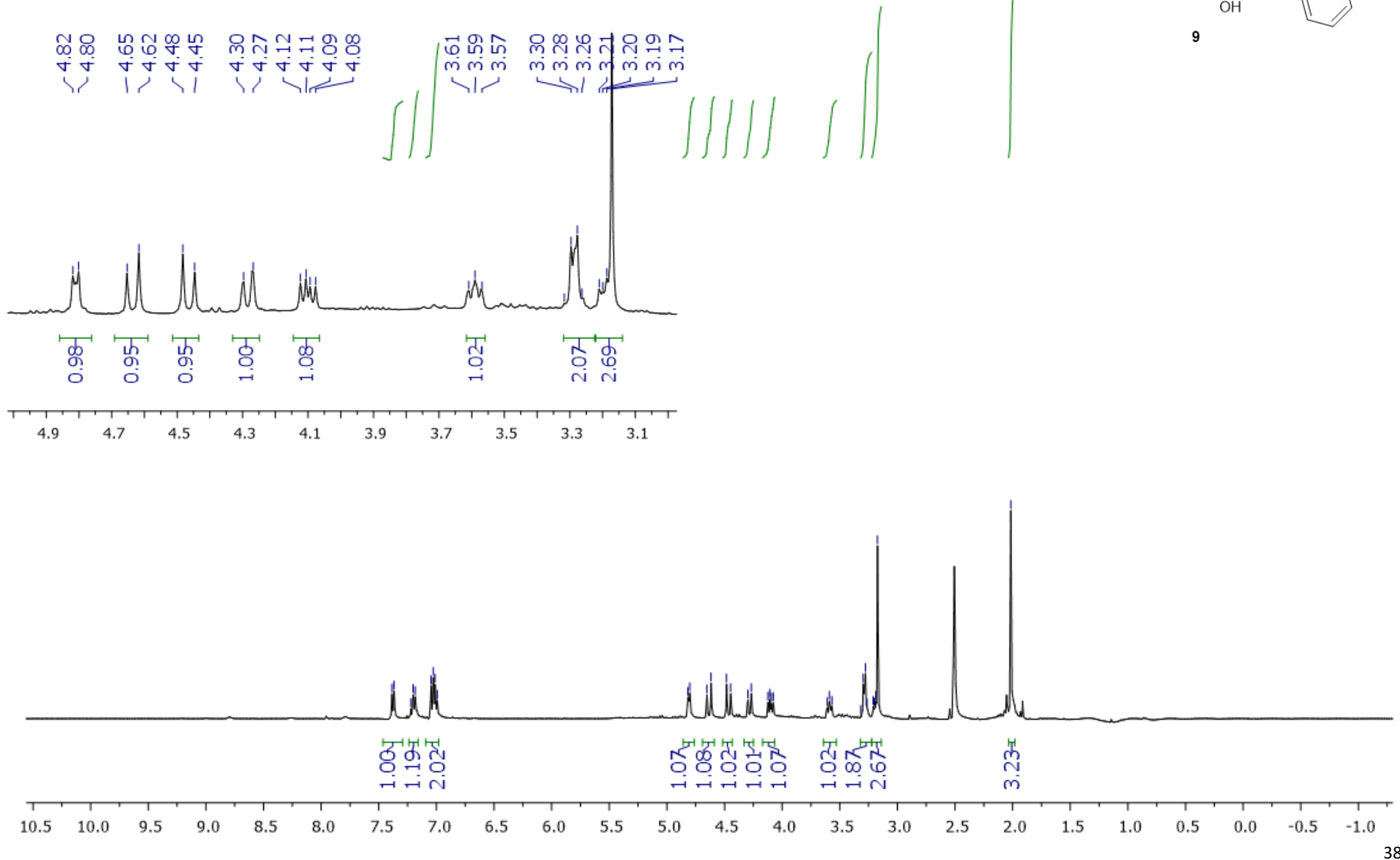
${ }^{13} \mathrm{C}\left(100 \mathrm{MHz}, \mathrm{DMSO}-d_{6}\right)$

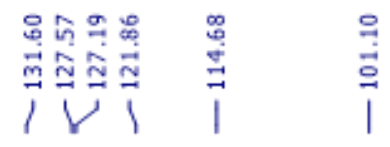

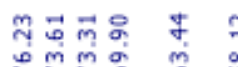

오숭

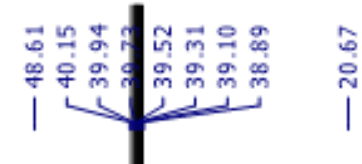

$\mathrm{HO}$
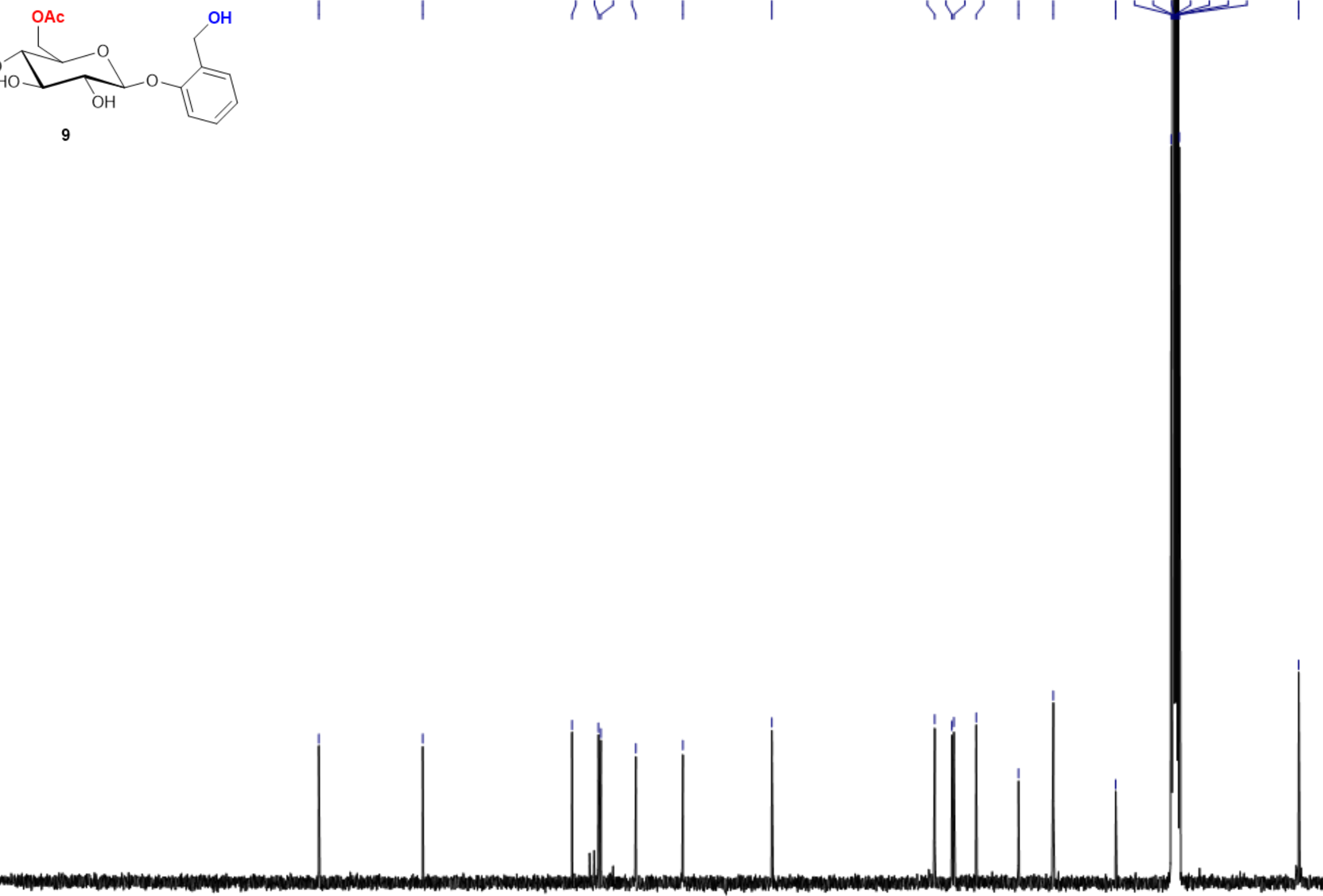

$\begin{array}{llll}210 & 200 \quad 190-180\end{array}$

$170 \quad 160$

150

140

$30 \quad 120$

$110 \quad 100$

f1 (MA)

$90 \quad 80$

70

60

$50 \quad 40$

$40 \quad 30$

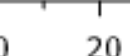

20
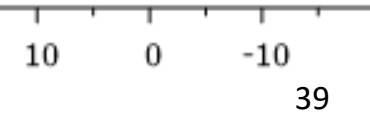


${ }^{1} \mathrm{H}-{ }^{1} \mathrm{H}$ COSY

und

Mun
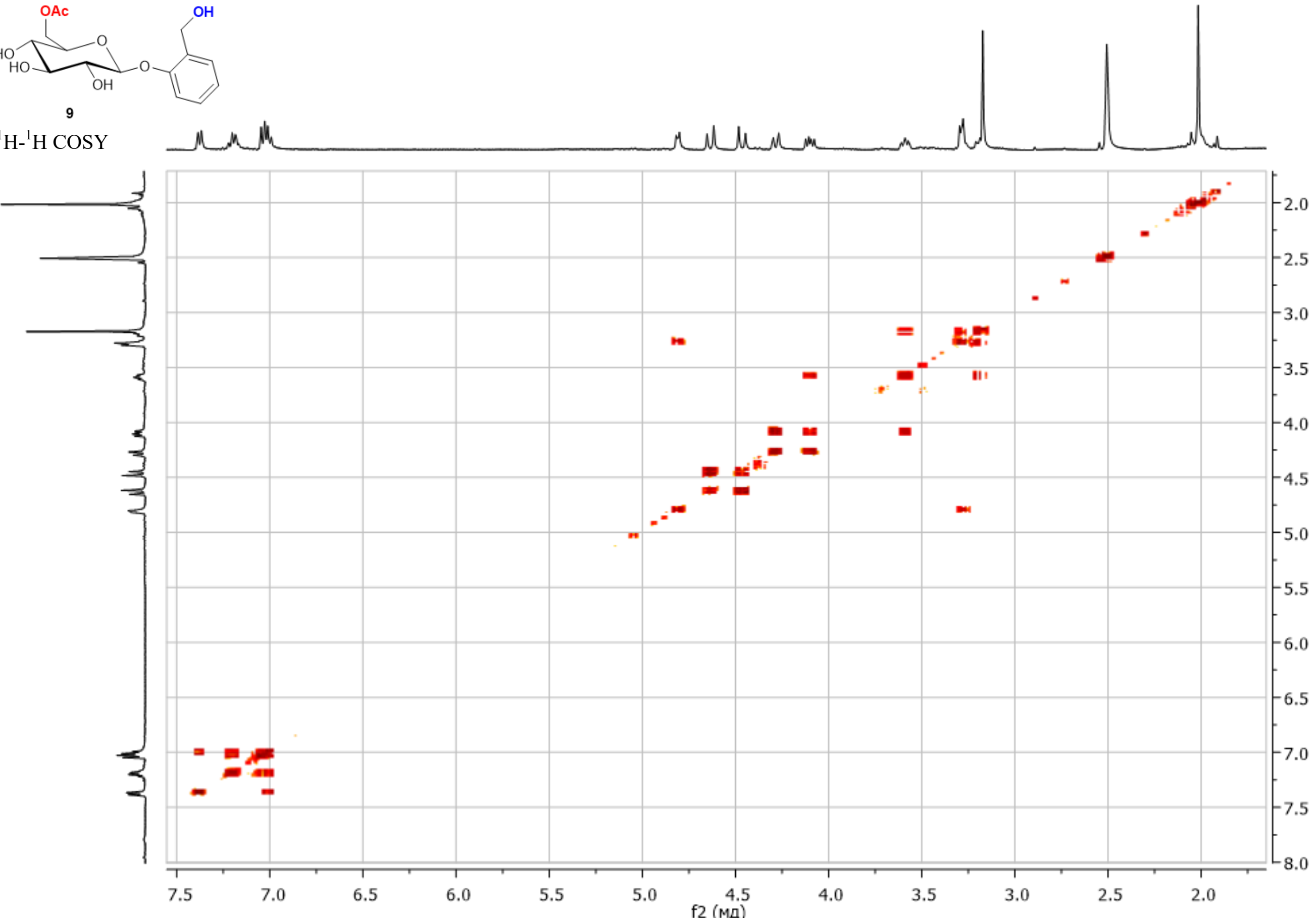


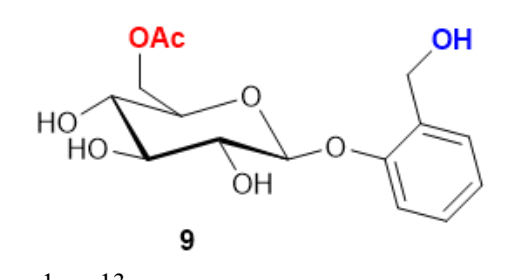

${ }^{1} \mathrm{H}-{ }^{13} \mathrm{C}$ HSQC

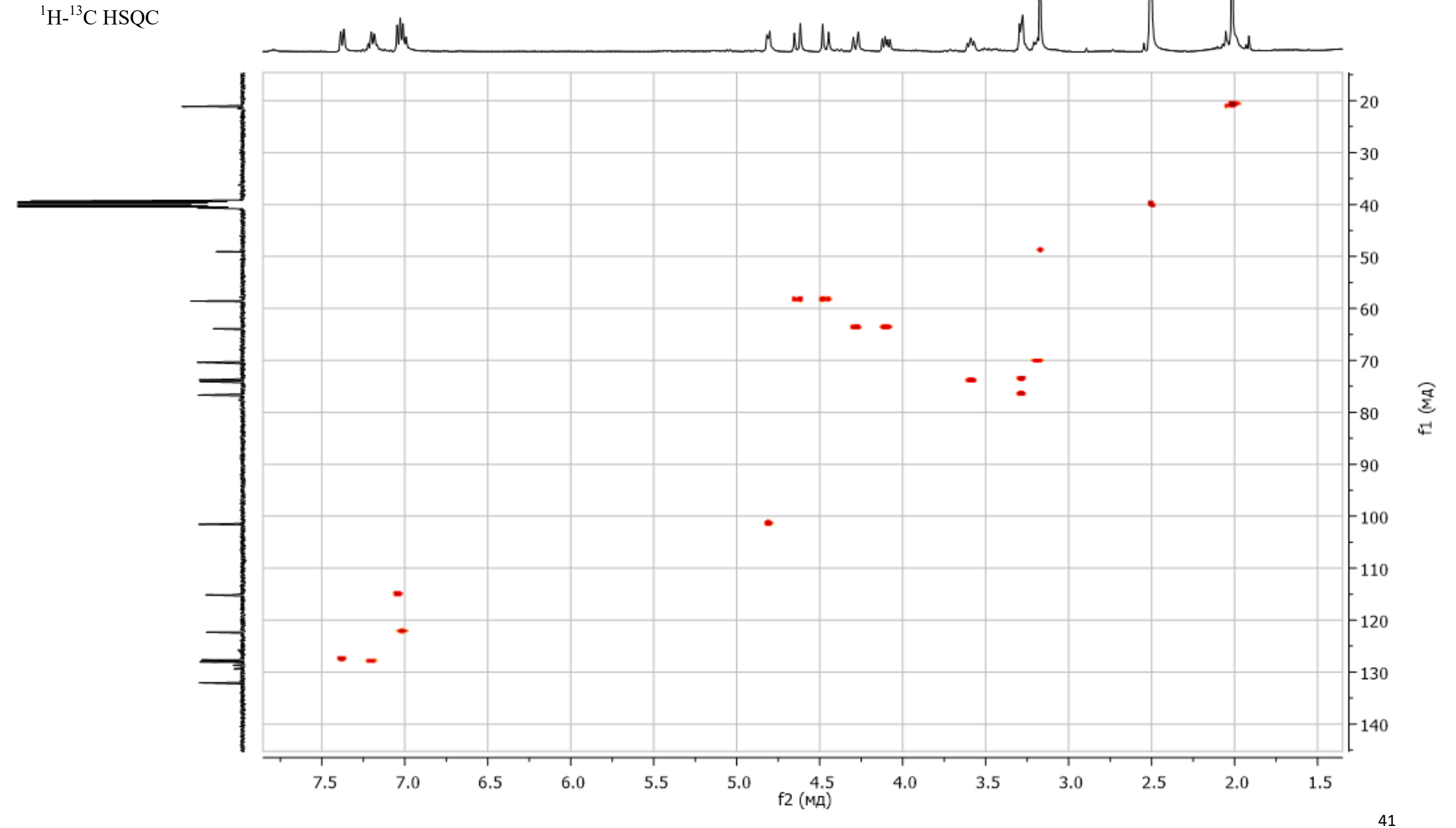




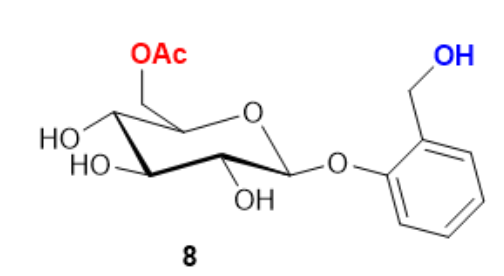

${ }^{1} \mathrm{H}-{ }^{13} \mathrm{C}$ HMBC

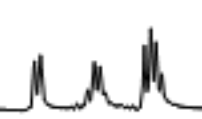

cullow and

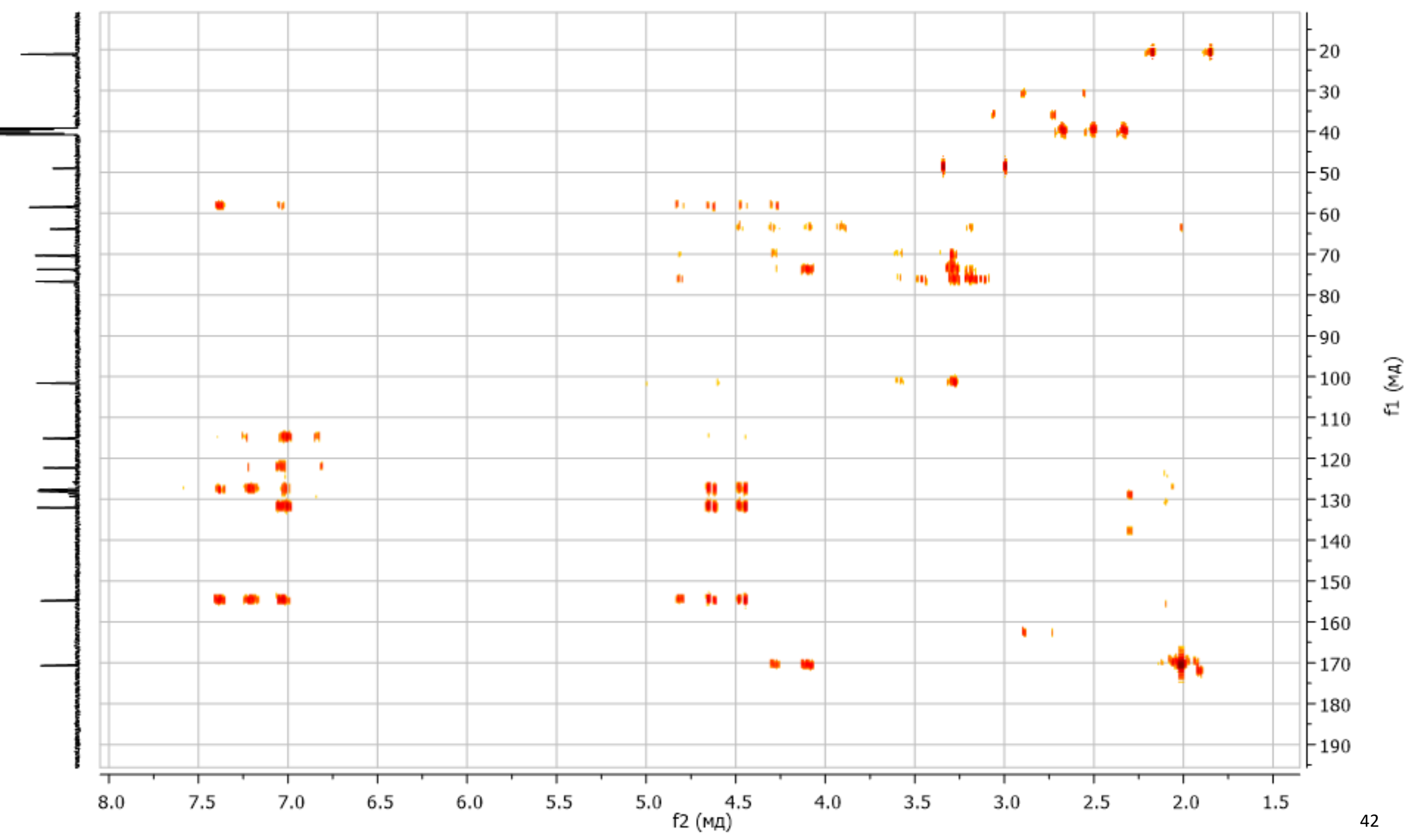


m m NNNNNNNNN

Lל

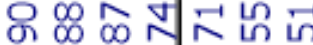

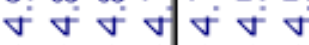

(

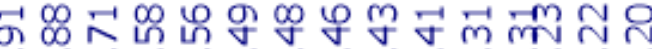

$\mathrm{mmmmmmmmm} \mathrm{mm}$

Ir

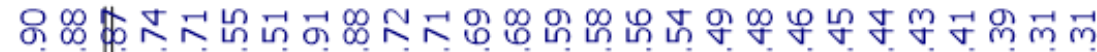

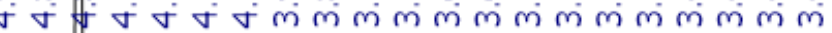

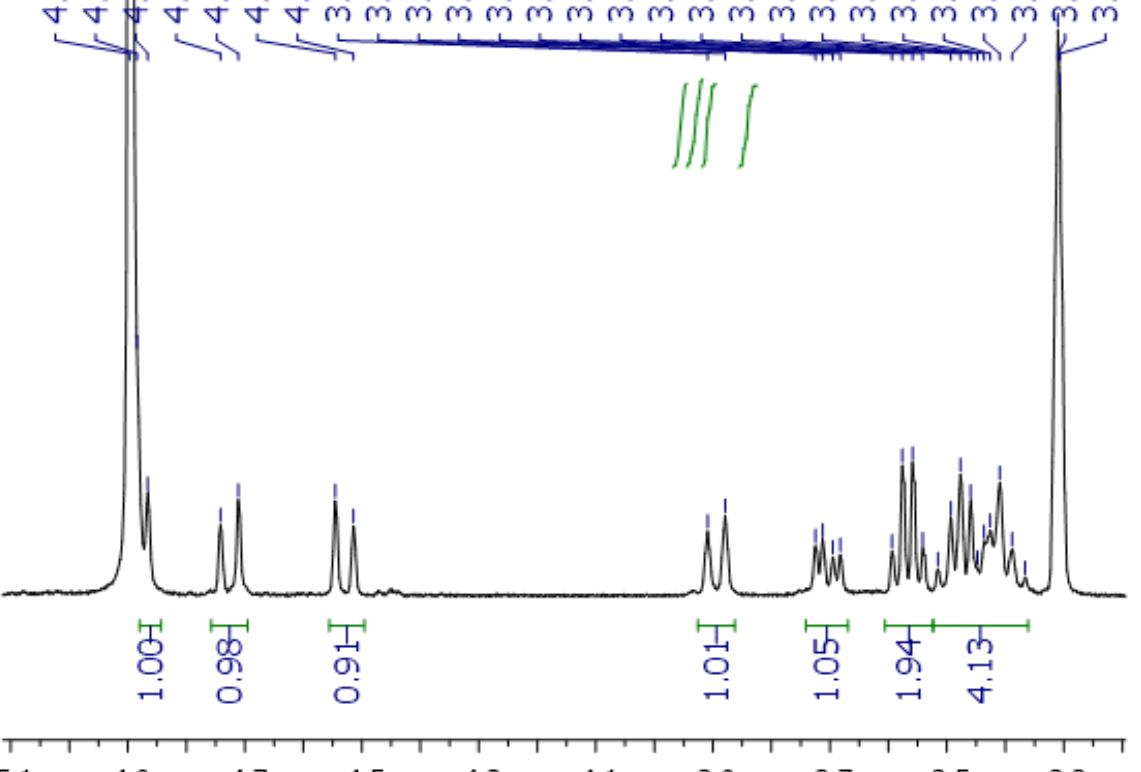

5.1

111
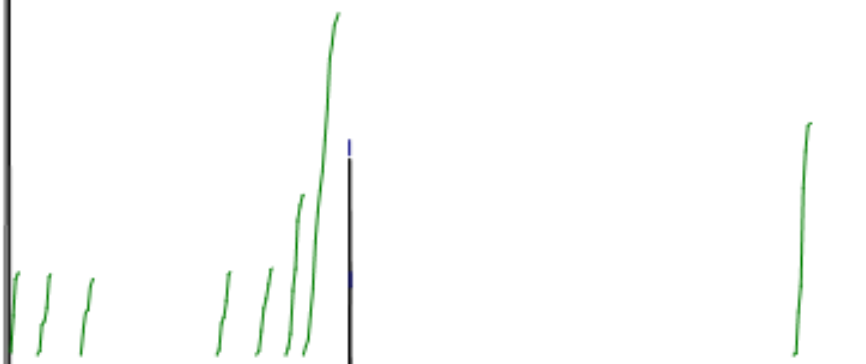

Ho

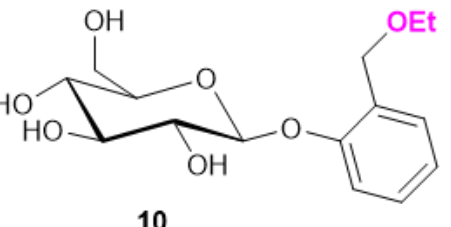

${ }^{1} \mathrm{H}\left(400 \mathrm{MHz}, \mathrm{MeOD}-d_{4}\right)$

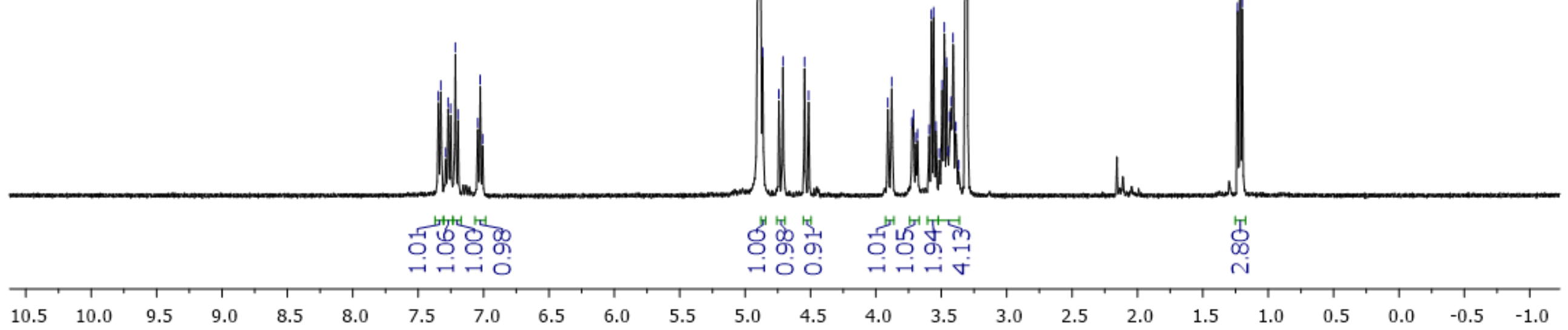


${ }^{13} \mathrm{C}\left(100 \mathrm{MHz}, \mathrm{MeOD}-d_{4}\right)$

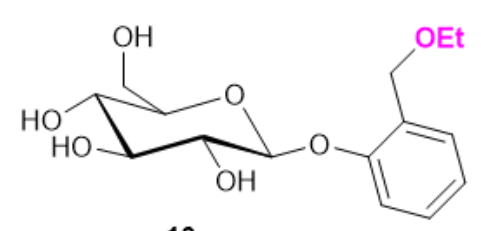

10
글ำ

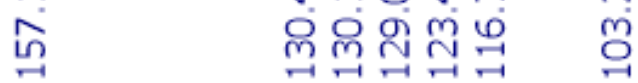

i
นุด

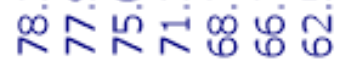

$\rightarrow 11$ m

gi gi gi go on

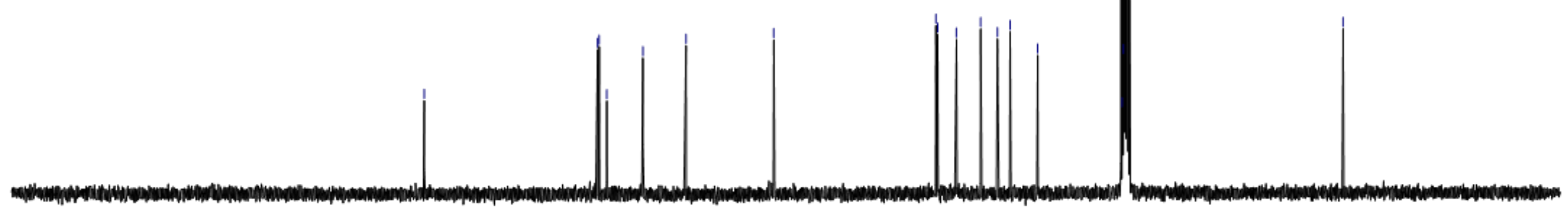

$220 \quad 210$

200

190

180

160

150

140

$130 \quad 120$

110

100

80

$70 \quad 60$

$60 \quad 50$

$40 \quad 30$

20

$10 \quad 0 \quad-10$ 

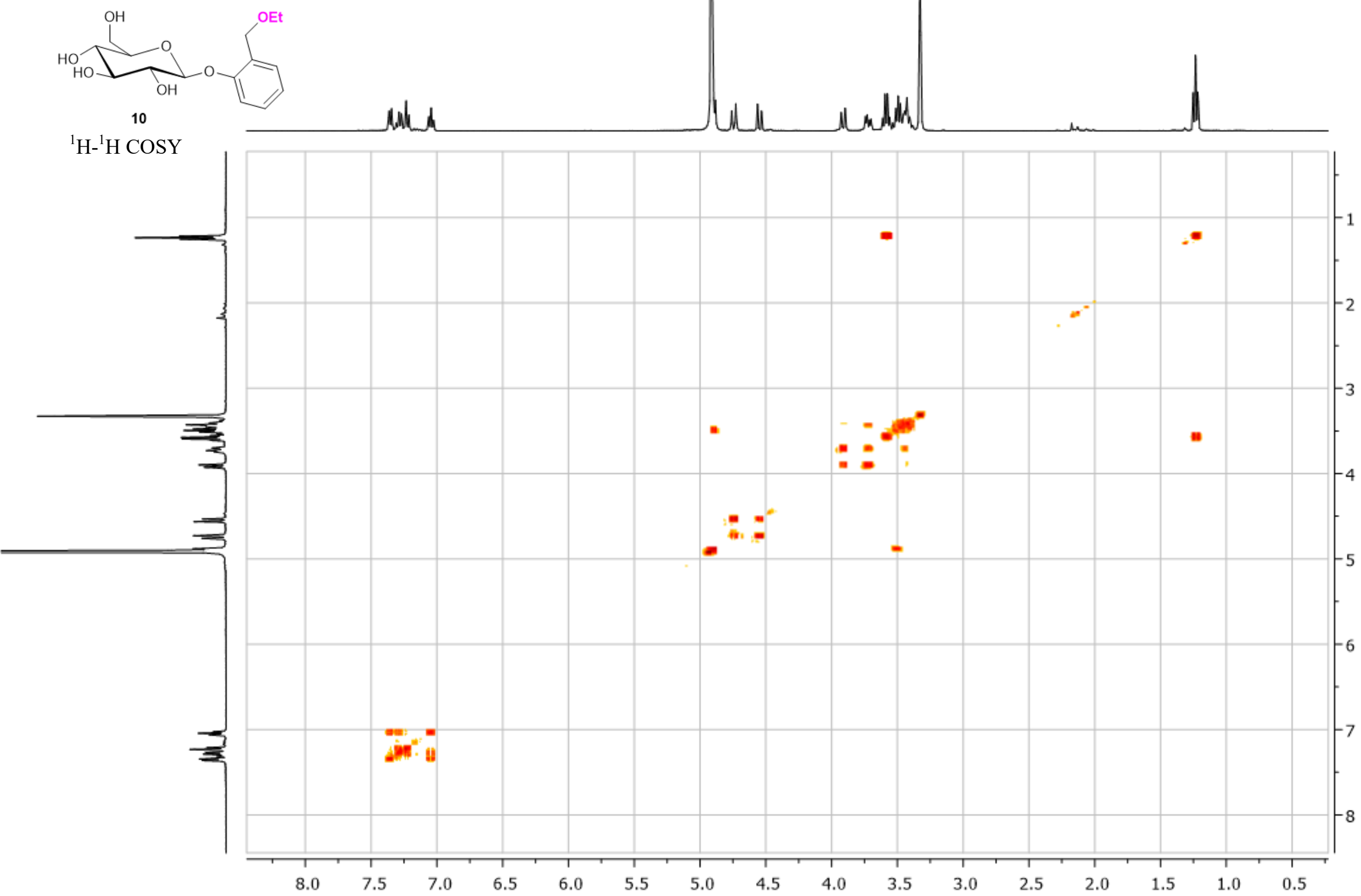


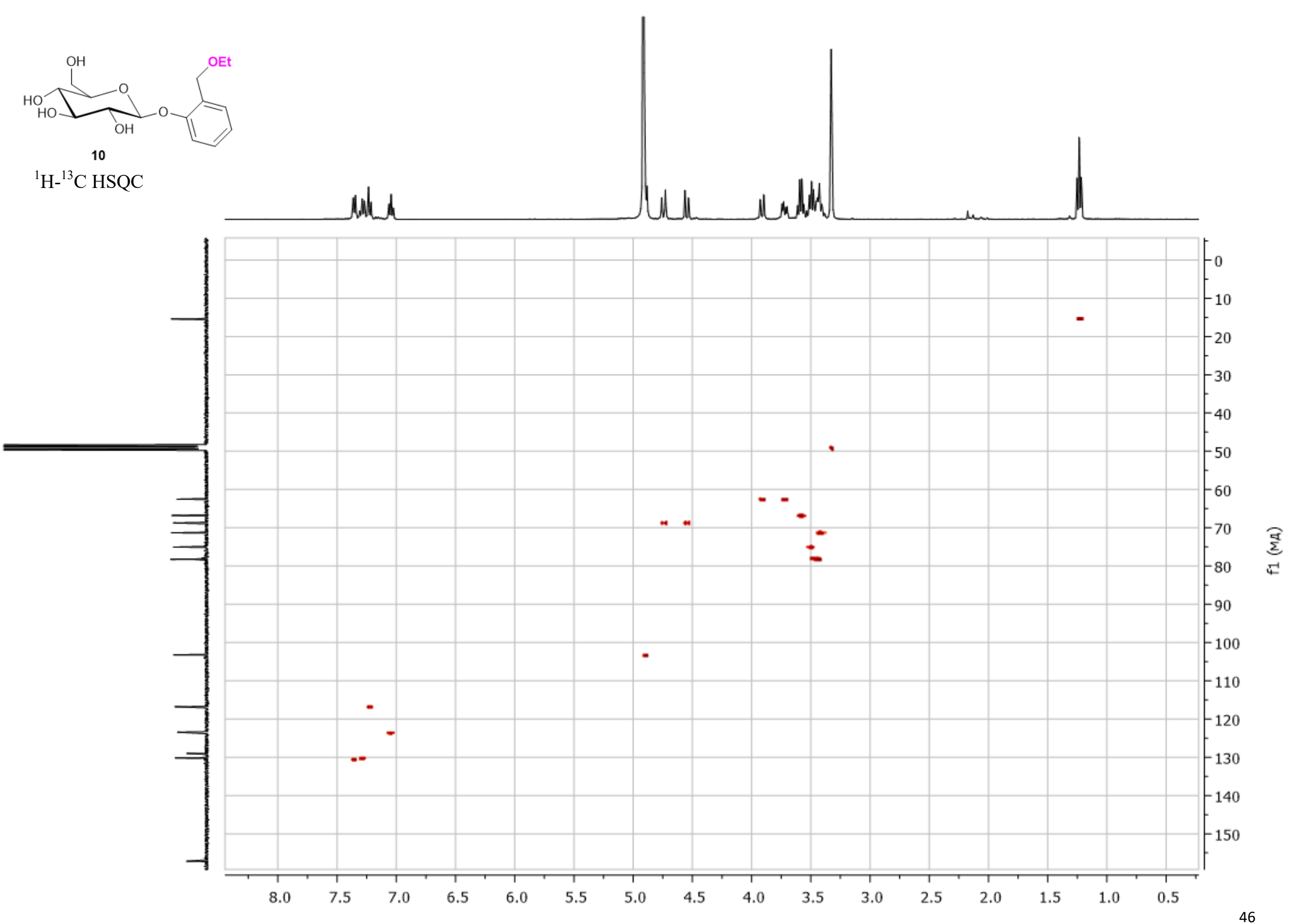


우있 N N N N N n

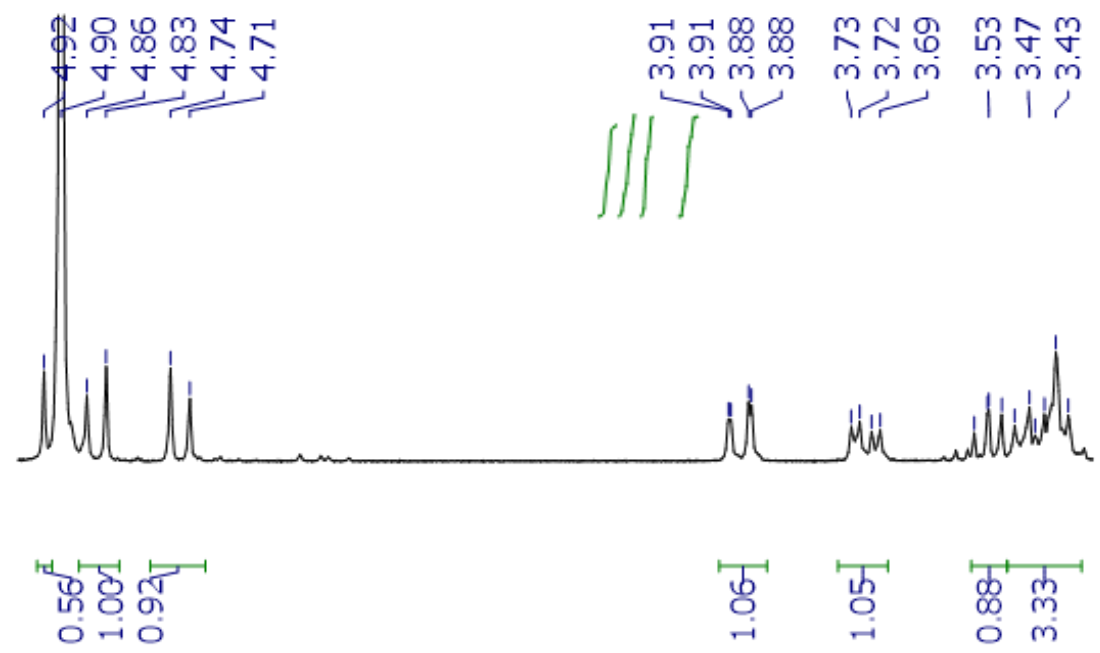

$\begin{array}{llllllllllllllll}4.9 & 4.8 & 4.7 & 4.6 & 4.5 & 4.4 & 4.3 & 4.2 & 4.1 & 4.0 & 3.9 & 3.8 & 3.7 & 3.6 & 3.5 & 3.4\end{array}$

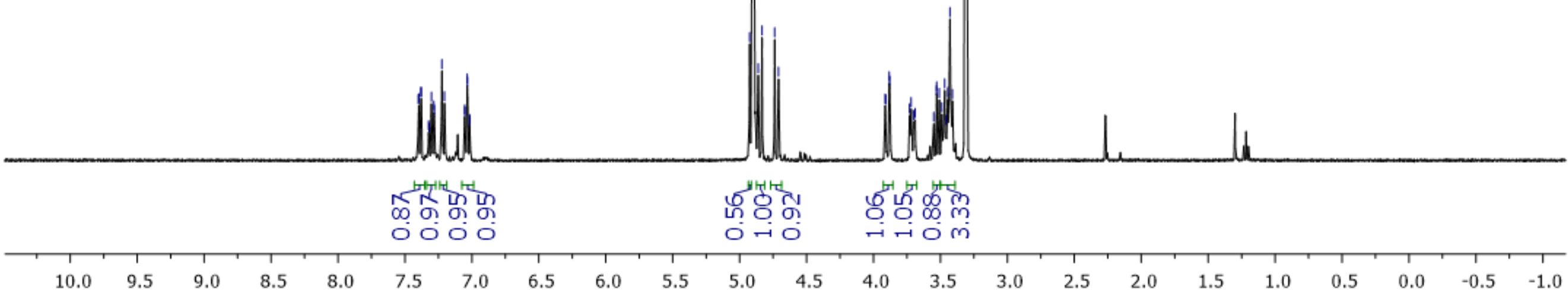


${ }^{13} \mathrm{C}\left(100 \mathrm{MHz}, \mathrm{MeOD}-d_{4}\right)$

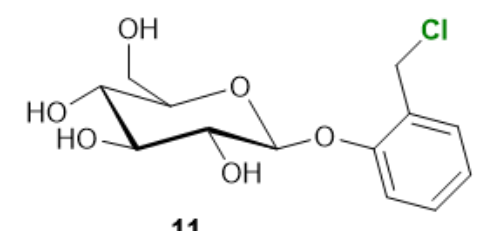

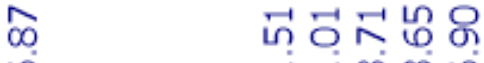

นn $\quad$ mंm

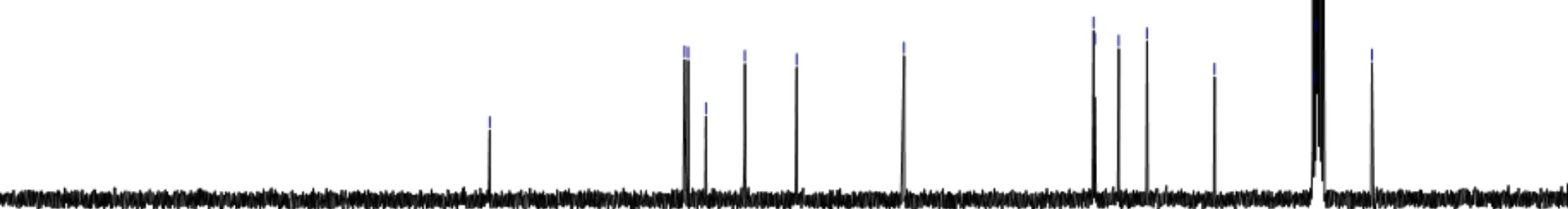


(OH

${ }^{1} \mathrm{H}-{ }^{1} \mathrm{H}$ COSY

Mindure Hula

$M$ m wh

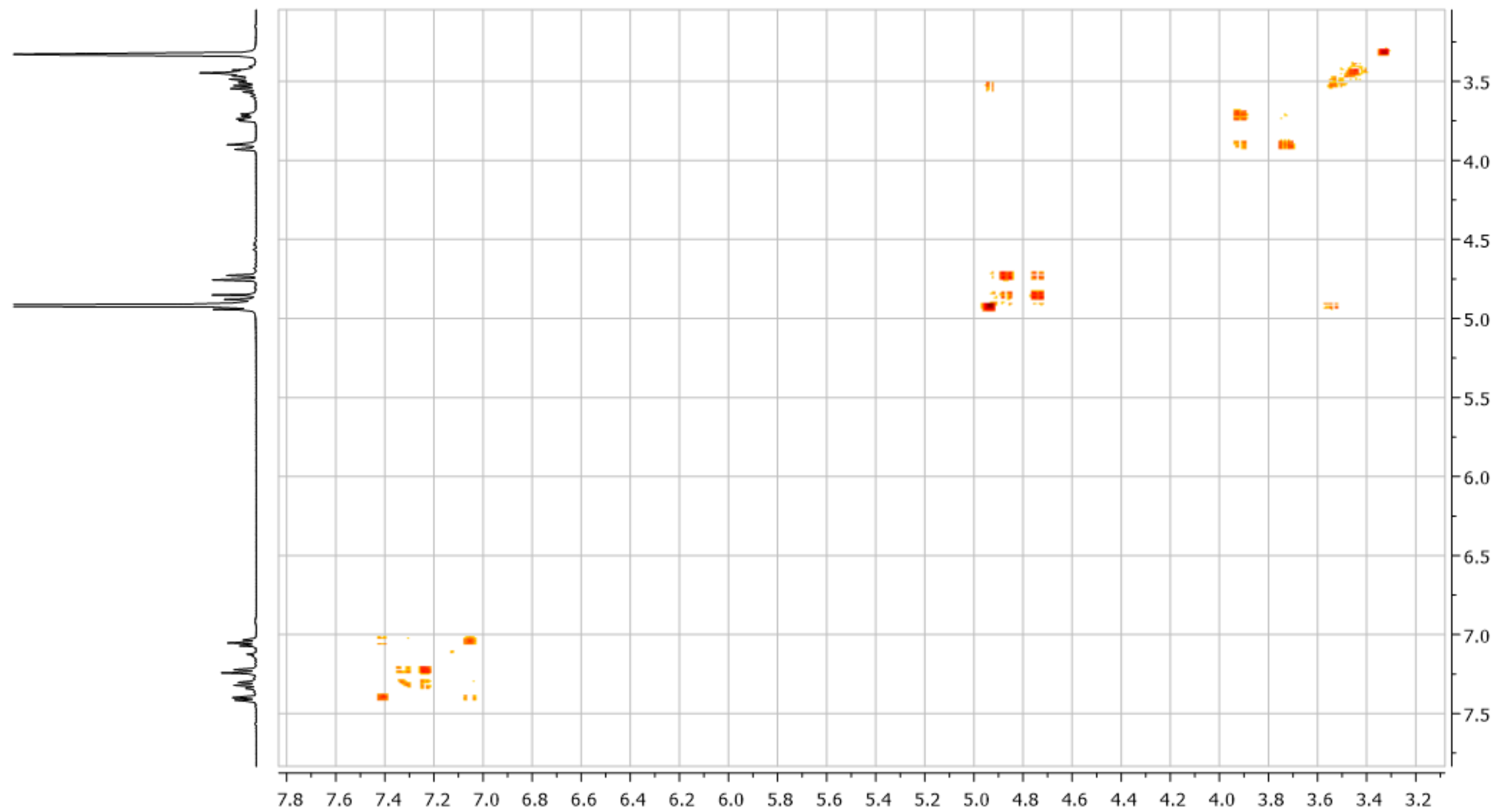




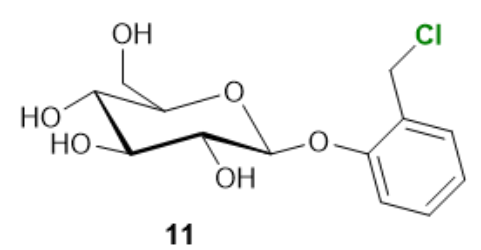

${ }^{1} \mathrm{H}-{ }^{13} \mathrm{C}$ HSQC

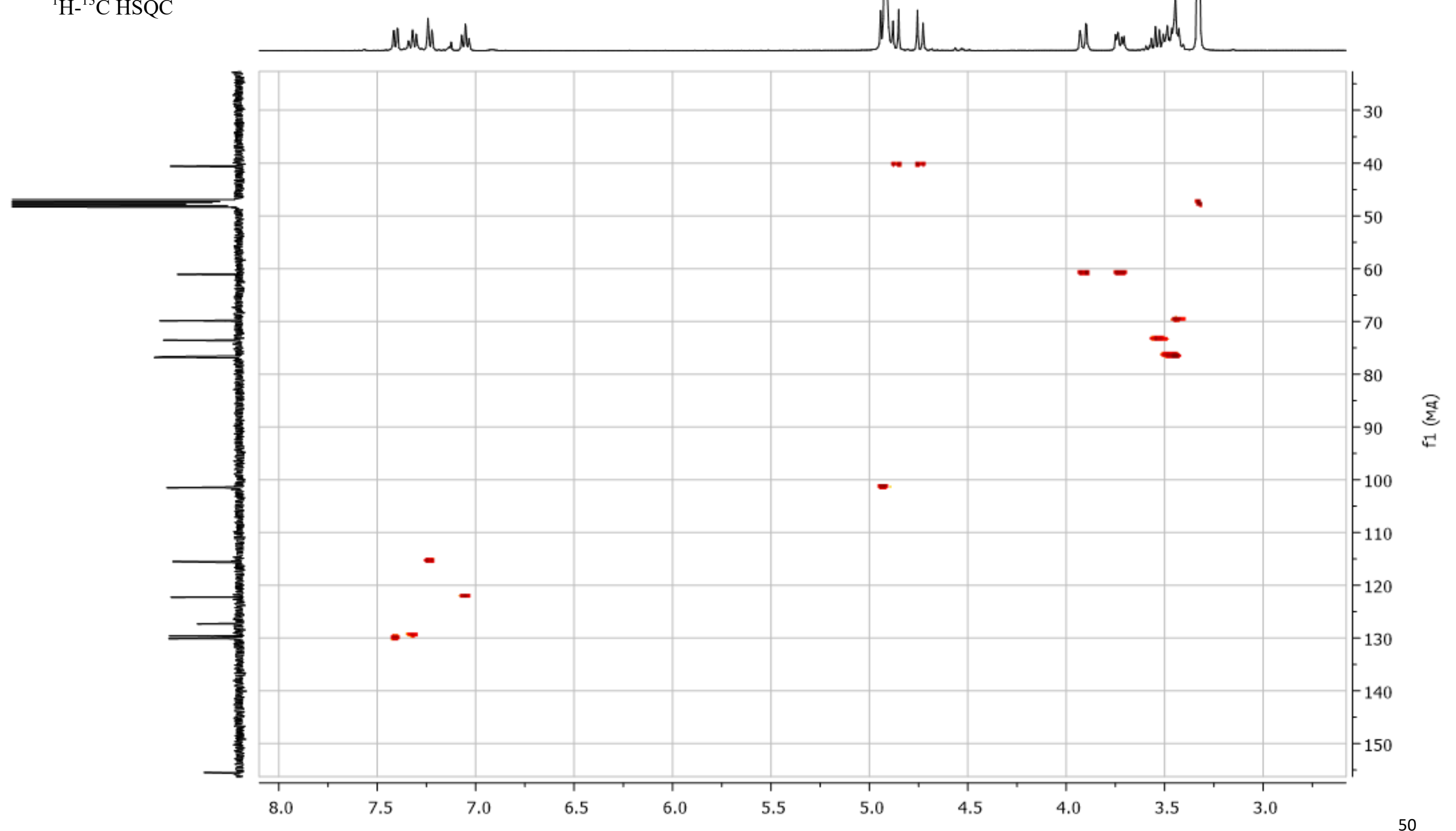




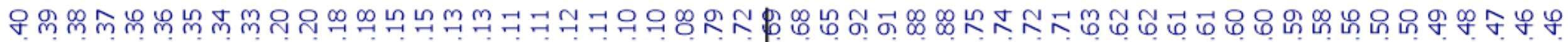

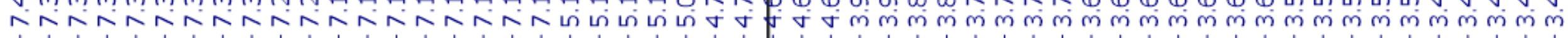

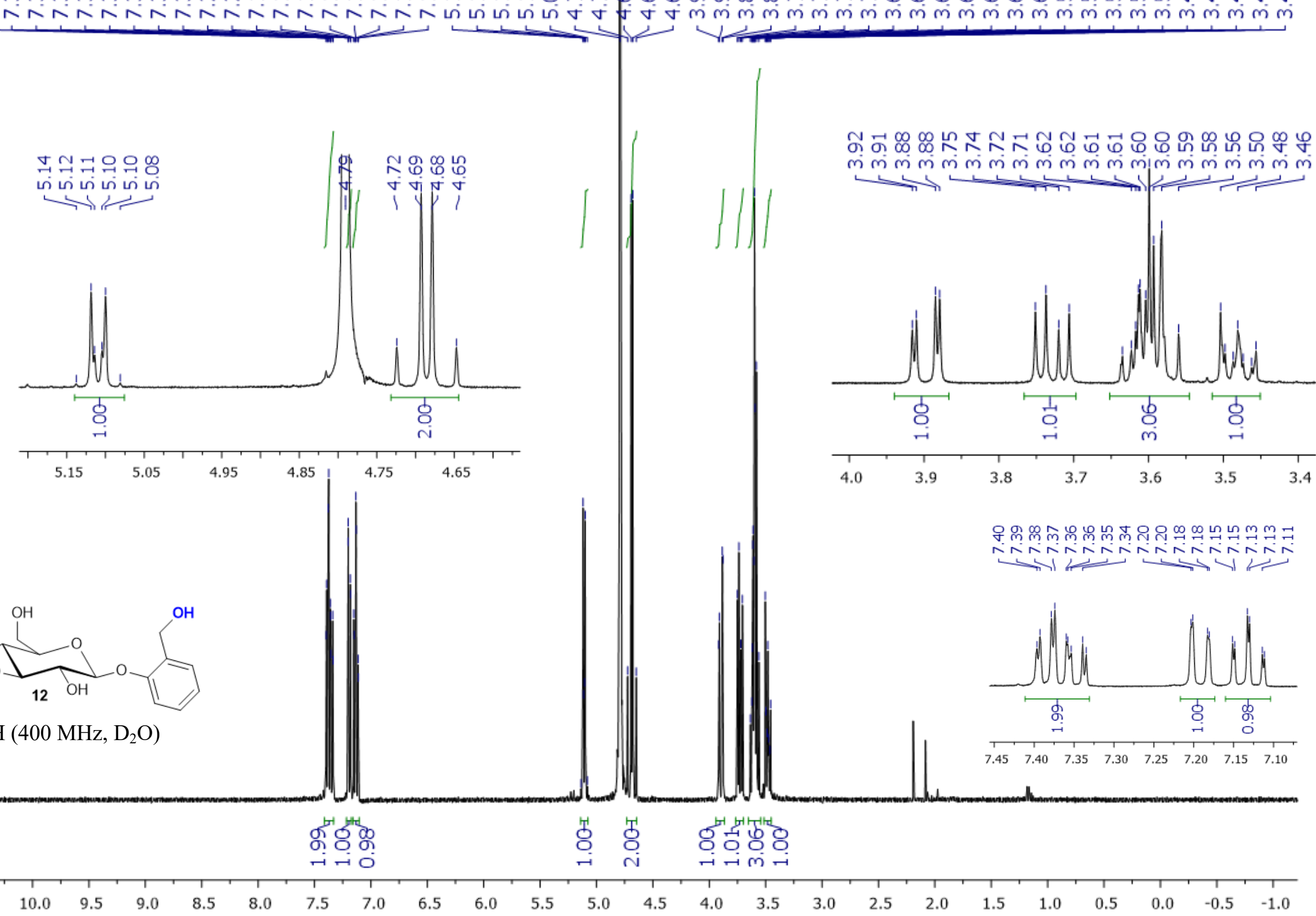




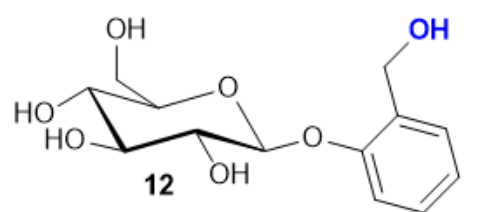

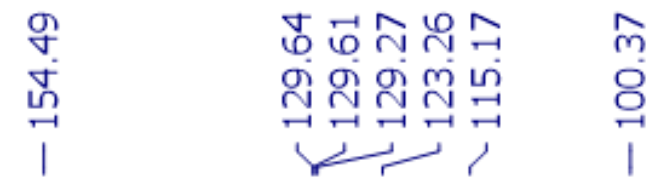

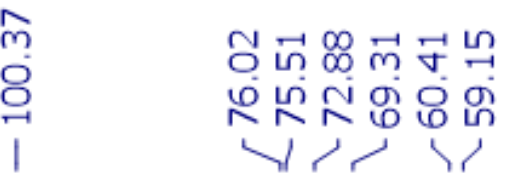

${ }^{13} \mathrm{C}\left(100 \mathrm{MHz}, \mathrm{D}_{2} \mathrm{O}\right)$
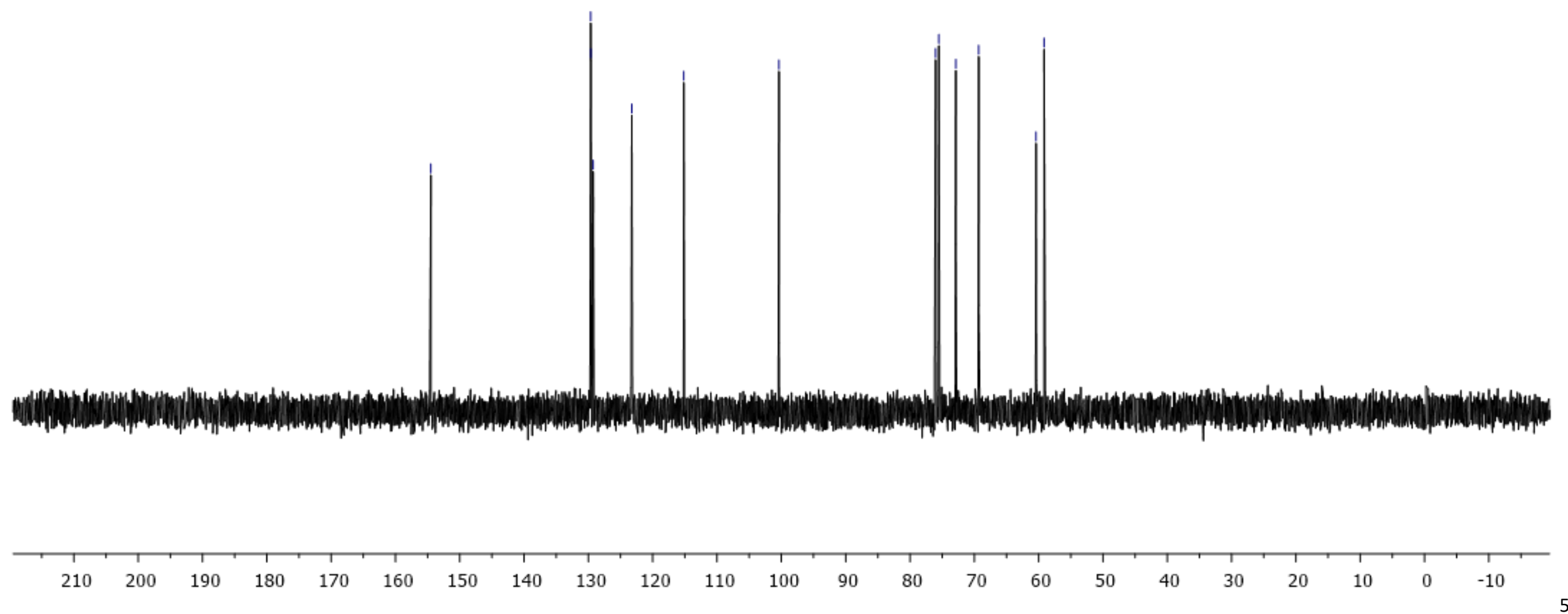
(OH

${ }^{1} \mathrm{H}-{ }^{1} \mathrm{H}$ COSY

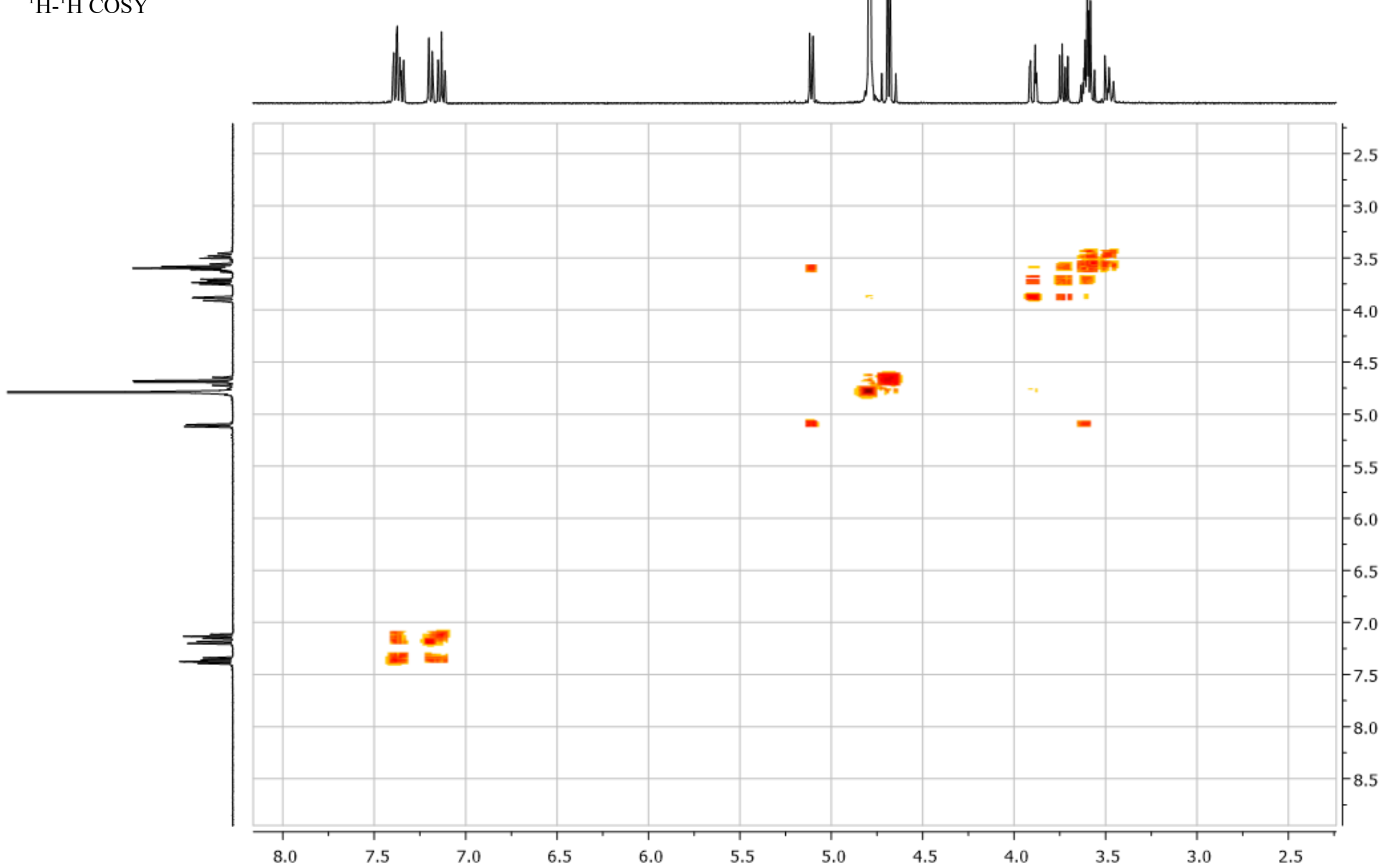


(OH

${ }^{1} \mathrm{H}-{ }^{13} \mathrm{C}$ HSQC

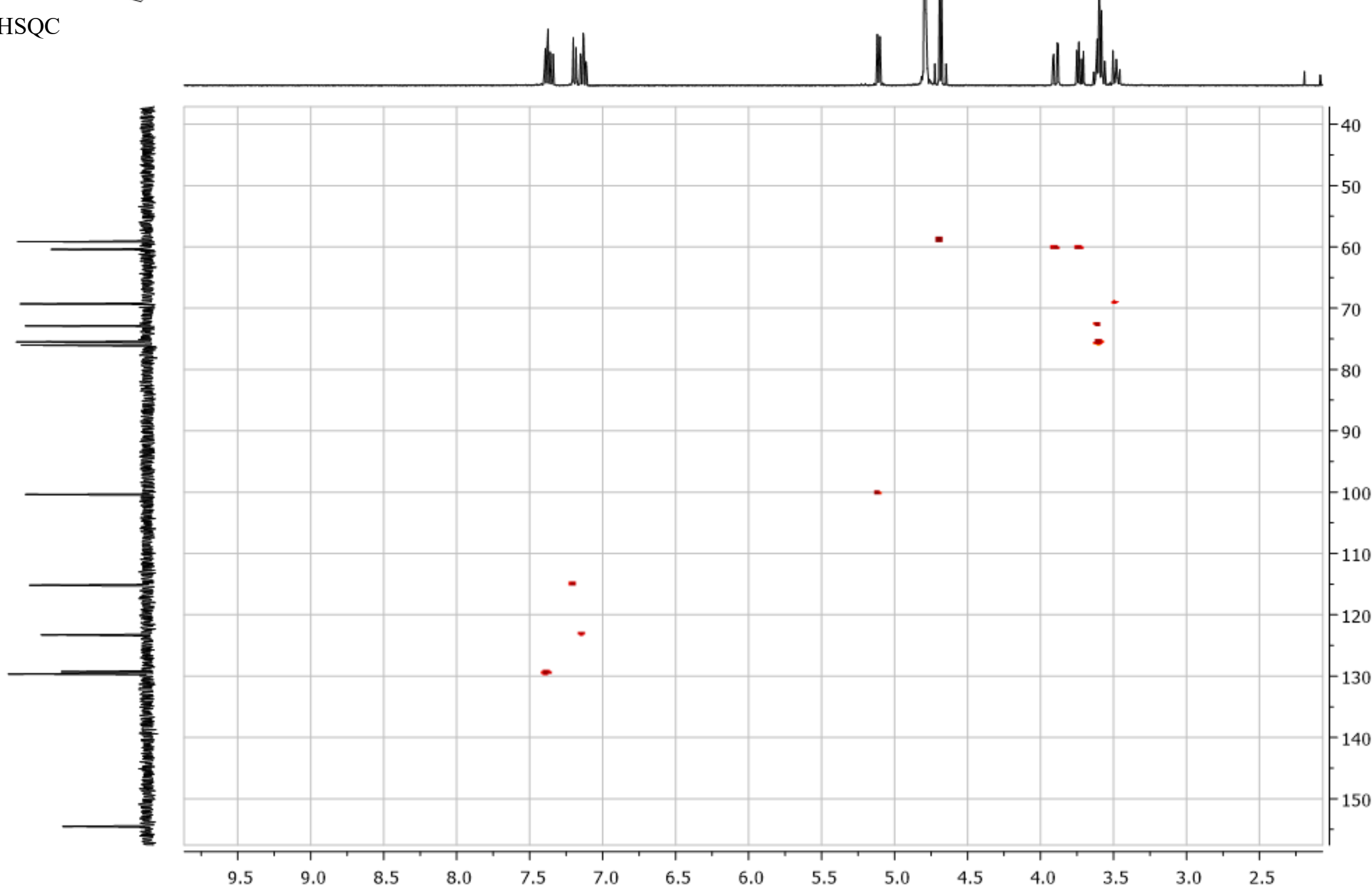

